\title{
Adición de la figura procesal separación de juicios a la Ley de Amparo en México
}

\author{
Adding figure procedural separation of trials under the \\ Law in Mexico
}

\begin{abstract}
Tlexochtli Rocío Rodríguez García
Doctora en Derecho por la Universidad de Xalapa; candidata a doctora por la Universidad de Armería España: maestra en Derecho Constitucional y Amparo por la Universidad Cristóbal Colón; maestra en Docencia Universitaria por la Universidad de Xalapa; especialidad en Docencia Universitaria; docente de las universidades Veracruzana de Xalapa, Centro Mexicano de Estudios de Posgrados.

Correo electrónico: tlexochtli@hotmail.com
\end{abstract}

\begin{abstract}
Resumen
El presente ensayo surge con motivo de la reforma a la Ley de Amparo en México, publicada en el Diario Oficial de la Federación, el 2 de abril de 2013, de la cual se abrogó la figura procesal de la acumulación prevista en los artículos $57,58,59,60,61,62,63,64$ y 65 , fundamentos que servían de base a contrario sensu a la jurisprudencia que establece la procedencia de la separación de juicio en materia de amparo, la cual se da en los casos en que en una demanda de amparo se reclamen actos emanados de juicios diversos, desvinculados entre sí, y dicha demanda ha sido admitida por el juez de Distrito, o bien, tal circunstancia es advertida durante la tramitación del juicio (hasta antes de la celebración de la audiencia constitucional), con motivo de los informes justificados que rindan la o las autoridades responsables.

En tales condiciones resulta beneficiosa la figura procesal de la separación de juicios en materia de amparo y no ir en contra de los criterios de la nueva Ley de Amparo. Se propone la integración de la separación de juicios en Ley de Amparo vigente, con el objetivo de crear certidumbre jurídica, eliminar denegación justicia pronta y expedita a quien acude a solicitar la protección de la Justicia Federal, así como para evitar el dictado de una sentencia incongruente consigo misma y consecuente una problemática en llevar su cumplimiento.
\end{abstract}

Palabras clave: Proceso, separación de juicio, amparo.

\begin{abstract}
This trial arises in connection with the amendment to the Law of Amparo in Mexico, published in the Official Journal of the Federation on 2 April two thousand thirteen of which the procedural figure of cumulation under Article 57 was repealed , 58, 59, 60, 61, 62, 63, 64 and 65 foundations forming the basis contrary to the jurisprudence of the origin of the separation of judgment on amparo, which occurs in cases that, in a claim for protection act emanating from various trials, unrelated to each other they are claimed, and this demand has been supported by the District Judge or such circumstance is noticed during the conduct of the trial (even before the celebration the constitutional court), the justified because of the reports rendered or the responsible authorities.

In such conditions it is beneficial to the procedural figure separation judgments on amparo and not go against the criteria of the new Law on Amparo, the integration of the separation of trials proposed under current law, the objective of creating legal certainty, eliminate denial prompt and expeditious justice who comes to seek the protection of the federal courts, and to avoid issuing a statement inconsistent with it a problematic same and consistent in taking compliance.
\end{abstract}

Keywords: Process, separation of judgment, amparo. 


\section{Résumé}

Ce texte se pose dans le cadre de l'amendement à la loi de Amparo au Mexique, publié au Journal officiel, le 2 Avril 2013, le chiffre de la procédure de cumul au titre de l'article 57 a été abrogée, 58, 59, 60, 61, 62, 63,64 et 65 fondations qui ont servi de base a contrario à la jurisprudence de l'origine de la séparation du procès en amparo, qui se produit dans les cas où dans une demande de protection émanant des actes de divers jugements, indépendants les uns des autres, ils sont revendiqués, et cette demande a été soutenue par le juge de district ou telle circonstance est remarqué au cours de la conduite de l'essai (avant même la conclusion de l'audience constitutionnel) à l'occasion de l'justifiée ou des rapports rendus par les autorités responsables. Dans ces conditions, il est la figure procédurale bénéfique de la séparation des jugements amparo et ne pas aller contre les critères de la nouvelle loi sur Amparo. l'intégration de la séparation de la loi des essais sur Amparo est proposé dans le but de créer une sécurité juridique, d'éliminer le déni rapide et la justice expéditive qui vient chercher la protection de la justice fédérale et d'éviter l'émission d'une déclaration incongrue avec lui-même et par conséquent un problème à mettre en conformité.

Mots-clés: Processus, séparation de procès prévu. 


\section{Adición de la figura procesal separación de juicios a la Ley de Amparo en México}

Tlexochtli Rocio Rodríguez García

\section{INTRODUCCIÓN}

Con anterioridad a la reforma de la Ley de Amparo de 1936, publicada en el Diario Oficial de la Federación el 2 de abril de 2013, existía la figura procesal de la acumulación prevista en los artículos 57, 58, 59, 60,61, 62, 63, 64 y 65 y en esa tesitura a contrario sensu se emitió un criterio jurisprudencial el cual establece la procedencia de la separación de juicio en materia de amparo, en los casos en que, en una demanda de amparo se reclamen actos emanados de juicios diversos, desvinculados entre sí, y dicha demanda ha sido admitida por el juez de Distrito, o bien, tal circunstancia es advertida durante la tramitación del juicio (hasta antes de la celebración de la audiencia constitucional), con motivo de los informes justificados que rindan la o las autoridades responsables.

En estos casos, se podía iniciar de manera incidental la separación de juicios, figura que al no estar específicamente regulada en la Ley de Amparo debía quedar contenida en una jurisprudencia, tomando como base el artículo 57 de esa Ley, que establece la acumulación, deduciéndolo en sentido contrario, por lo que, salvo los casos que preveía los supuestos de la acumulación podía llevarse a cabo la separación de juicio.

Con la reforma a la Ley de Amparo, antes precisada, el legislador derogó el capítulo relativo a la figura procesal consistente en la acumulación prevista en los referidos artículos, incluyendo el numeral 57, el cual daba fundamento a la jurisprudencia que establecía la procedencia de la separación de juicio en estudio. 
La figura que se suscitaba cuando del texto de la demanda de amparo se advertía que el quejoso reclamaba actos provenientes de diversos juicios, o durante la tramitación del juicio al momento de rendir los informes justificados las autoridades responsables, se advertía una pluralidad de actos distintos entre sí sin guardar ninguna relación.

En tal circunstancia, se podía iniciar en vía incidental la separación de juicio con el fin de evitar el dictado de una sentencia incongruente consigo misma, con la consecuente problemática que implicaría su cumplimiento; lo anterior, fundamentado en la jurisprudencia número P./J. 76/97, sustentada por el Pleno de la Suprema Corte de Justicia de la Nación, visible en la página 118, del tomo VI, correspondiente al mes de septiembre de 1997, publicada en el Semanario Judicial de la Federación y su Gaceta, $9^{a}$ Época, la cual servía de base a la multicitada separación de juicios en materia de amparo, la cual tuvo su origen dado que dicha separación no se encuentra prevista en la Ley de Amparo; establecida con el objetivo de crear certidumbre jurídica, y elimina denegación y justicia pronta y expedita a quien acuda a solicitar la protección de la Justicia Federal.

Así como para evitar el dictado de una sentencia respecto de un acto que legalmente no le compete conocer, en los casos en que se plante demanda de garantías de la cual advierta que se cuestiona la constitucionalidad de actos cuya competencia corresponda, tanto a un juez de Distrito como a un Tribunal Colegiado.

Esta separación de juicios, daba oportunidad al quejoso para que pudiera acreditar mediante pruebas la inconstitucionalidad de los actos que reclama y que son propios del conocimiento del juez de Distrito, esto es, cuando se reclama una resolución que pone fin a un procedimiento seguido en forma de juicio ante el cual no existe medio ordinario de defensa en su contra $\mathrm{y}$, a su vez, se cuestiona un acto proveniente de una autoridad diversa de un tribunal judicial, administrativo o del trabajo; toda vez que no debe soslayarse que solo en el amparo indirecto se permite el ofrecimiento y admisión de pruebas tendentes a demostrar la inconstitucionalidad de los actos reclamados, mientras que en el amparo directo el acto debe ser analizado tal y como fue probado ante la responsable.

Lo anterior, desde luego, siempre y cuando los actos reclamados en la demanda tengan existencia autónoma y no dependan entre sí, es decir, que no sean consecuencia uno del otro, o que persigan el mismo objeto procesal, pues de resultar así, no debe decretarse la separación, en virtud de que no es factible dividir la continencia de la causa.

Por lo que, con la reforma a la Ley de Amparo publicada el 2 de abril de 2013, en el Diario Oficial de la Federación, se derogaron los artículos relativos a la acumulación en el juicio de amparo y como consecuencia a contrario sensu la separación de juicios, que se encontraba fundamentada en criterio jurisprudencial a su vez sustentado en el artículo 57 de la Ley de Amparo, aplicado a contrario sensu.

Sin embargo, es de considerar que si bien no existe un impedimento material para efectuar un examen de los actos reclamados en un solo juicio de amparo, sin importar 
que entre ellos no haya conexidad, no significa que tal estudio debe hacerse, porque el impedimento es de orden jurídico y tiene su apoyo legal en el artículo en que se señalan los casos de acumulación. Sostener lo contrario llevaría al absurdo de que en un solo juicio, por la mera circunstancia de que se tratara de un solo quejoso, se analizaran actos desvinculados, de naturaleza tan disímbola, como pudieran ser actos provenientes de autoridades civiles, penales, administrativas e, incluso, de fueros diversos, lo que desde luego no es aceptable.

Actualmente la legislación de amparo no precisa qué trámite se debe realizar cuando en una demanda de amparo, se reclaman actos que no guarden ninguna relación entre sí, en una sola demanda de amparo.

\section{ANTECEDES DEL JUICIO DE AMPARO}

Dentro de la península de Yucatán en su descontento por el régimen centralista enmarcado en la entonces vigente Constitución de 1836, comúnmente conocida como "Las Siete Leyes de 1836" amenazó con su intención de separarse de la República mexicana. Con la consiguiente preocupación, se le otorgó la facultad de legislar su propio régimen jurídico, como si se tratase de un Estado federalista dando origen a la Constitución de Yucatán del 31 de marzo de 1841 (Burgoa, 2010, p. 123).

Esta Constitución tuvo a bien recoger un proyecto en el artículo 53, elaborado por Manuel Crescencio Rejón, que expresaba textualmente:

Corresponde a este tribunal [la Corte Suprema de Justicia] reunido: $1^{\circ}$. Amparar en el goce de sus derechos a los que pidan su protección contra las providencias del Gobernador o Ejecutivo reunido, cuando en ellas se hubiese infringido el Código Fundamental o las leyes, limitándose en ambos casos a reparar el agravio en la parte que procediere (Burgoa, 2010, p. 89).

Así se habló por primera vez en el derecho legislado del amparo decretado por órganos jurisdiccionales para combatir agravios contra las garantías individuales, en el proyecto de Rejón y en la Constitución yucateca de 1841.

Tiempo después este juicio se plasmó con la colaboración de Mariano Otero en el Congreso Constituyente, sobre el artículo 25 del Acta constitutiva y de reformas de 1847, con lo que se estableció el Juicio de Amparo a nivel federal, para después plasmarse en la Constitución Federal de los Estados Unidos Mexicanos de 1857, este juicio es reglamentado finalmente en la Ley Orgánica Constitucional sobre el Juicio de Amparo de 20 de enero de 1869, siendo esta una aportación de México al mundo y, 60 años más tarde en la Constitución Política de los Estados Unidos Mexicanos de 1917, actualmente vigente en el país, a través de la Ley de Amparo de 1936 reformada en 2013 y la cual es reglamentaria de los artículos 103 y 107 constitucionales, abrogada por la reforma de 2 de abril de 2013.

Por lo que se concluye que con el juicio de amparo se garantiza la debida aplicación de la Constitución Política, ya que ella debe prevalecer sobre cualquiera 
otra ley, y sus disposiciones referentes a los derechos fundamentales, que garantiza en sus primeros 28 artículos, deben ser norma limitativa de la actuación de todas las autoridades, porque tales derechos son base imprescindible de la convivencia social, y en consecuencia, su efectividad práctica debe ser reconocida y aplicada por los órganos gubernativos, a fin de que sus actividades se desarrollen sin violación de ninguno de los derechos fundamentales.

\section{Concepto de juicio de amparo}

El juicio de amparo es un medio procesal constitucional del ordenamiento jurídico mexicano que tiene por objeto específico

hacer reales, eficaces y prácticos los derechos humanos establecidos en la Constitución, buscando proteger de los actos de todas las autoridades sin distinción de rango, inclusive las más elevadas, cuando violen dichas garantías. Está regulado por los artículos 103 y 107 de la Constitución Federal y la Ley de Amparo (Burgoa, 2010, p. 89).

Se basa en la idea de limitación del poder de las autoridades gubernamentales, la cual jurídica y lógicamente resulta de la decisión de la soberanía que en los primeros artículos de la Constitución garantiza los derechos fundamentales. Tan solo los actos emitidos por la Suprema Corte de Justicia y así como actos relacionados con materia electoral quedan fuera de su acción.

En las ediciones de la Suprema Corte de Justicia de la Nación, se encuentra que se conceptualiza al juicio de amparo como “... un procedimiento autónomo con características específicas propias de su objeto, que es el de lograr la actuación de las prevenciones constitucionales a través de una contienda equilibrada entre el gobernador y el gobernante (Suprema Corte de Justicia, 2012, p. 65)".

Es considerado como un medio de control jurisdiccional del sistema jurídico mexicano, en adición a la acción de inconstitucionalidad y la controversia constitucional. A diferencia de estos dos últimos, el juicio de amparo es promovido por cualquier particular que considere que sus derechos humanos y garantías constitucionales han sido violados por alguna autoridad.

Este juicio de garantías se extiende a un minucioso control de la constitucionalidad y legalidad, que consiste, primero, en revisar la aplicación concreta de la ley hecha por la autoridad responsable, y segundo, en examinar si el acto reclamado expresa su fundamento legal y motivo de hecho, con el objeto de determinar si ese fundamento y ese motivo son o no pertinentes, pero todo esto restringido a los actos de las autoridades que tengan alguna relación con los derechos del hombre garantizados en la Constitución. Asimismo, el juicio de amparo tiene como fin evitar que actos de autoridades contravengan directamente la Constitución o que las leyes en que dichos actos se apoyan sean contrarias a la Constitución. 
El juicio de amparo tiene dos características fundamentales:

Se trata de un juicio impugnativo autónomo, es decir, no consiste en un recurso o apelación que meramente constituya otra instancia, sino que implica iniciar un proceso completamente nuevo; no es parte del mismo juicio, sino que es otro juicio.Es un juicio de garantías, es decir, no obstante que se trata de un juicio de orden constitucional, el juzgador no se limita a ver si existieron violaciones constitucionales, sino que puede incluso dejar subsistentes las violaciones constitucionales, siempre que se demuestre que nadie resultó afectado en sus derechos fundamentales. Asimismo, puede exigir la suspensión de un acto que, no obstante ser constitucional, viole las garantías individuales. En otras palabras, no se ocupa de cualquier violación a la Constitución, sino de aquellas cuyo resultado es el menoscabo de un derecho humano o garantía constitucional, que resulta en daño personal y directo a una o varias personas concretas (Suprema Corte de Justicia, 2012, p. 123).

El juicio de amparo es un procedimiento judicial propiamente dicho, y entraña una verdadera contención entre la persona agraviada que lo promueve y la autoridad que dicho promovente considera que ha afectado o trata de afectar sus derechos garantizados en la Constitución:

El agraviado o «quejoso» asume el papel de actor en la controversia y la autoridad designada como responsable interviene como demandada;

La materia de la controversia es el acto concreto o la omisión de autoridad que el interesado considera lesivo de sus garantías individuales;

La decisión incumbe, en única o en última instancia, a los tribunales judiciales federales.

\section{Principios fundamentales del juicio de amparo}

Se llama principios del amparo a un grupo de instituciones procesales establecidas en el artículo 107 de la Constitución Política de los Estados Unidos Mexicanos y en la ley secundaria, que sirven de base o fundamento al ejercicio de la acción de amparo y a la sentencia que en él se dicte.

Los principios del juicio de amparo se clasifican en:

1) Los relativos al ejercicio de la acción de amparo (instancia de parte agraviada, agravio personal y directo y, definitividad); $\mathrm{y}$

2) Los referentes a la sentencia de amparo (estricto derecho y relatividad de la sentencia) (Suprema Corte de Justicia, 2012, p. 68).

El juicio de amparo se rige por los siguientes principios:

a) Principio de iniciativa o instancias de parte agraviada.

b) Principio de existencia de agravio personal y directo. 
c) Principio de prosecución judicial.

d) Principio de la relatividad de las sentencias.

e) Principio de definitividad.

f) Principio de estricto derecho.

g) Principio de celeridad (Suprema Corte de Justicia, 2012, p. 68).

\section{Principio de iniciativa o instancias de parte agraviada}

Por este principio debe de entenderse que el juicio no se tramitará de oficio por ninguna autoridad judicial, solo por petición del propio afectado, su apoderado o representante legal (o por cualquier otra persona pero solo en los casos en que el afectado esté privado de su libertad personal).

La instancia de parte agraviada implica que el ejercicio de la acción de amparo solo corresponde a la persona física o moral que considera que ha sido afectada por un acto de autoridad.

El principio de instancias de parte agraviada establece que el juicio de amparo solo se podrá iniciar cuando el gobernado lo solicita, es decir:

Cuando la persona que se considera afectada por un acto de autoridad pide o "inta" a los tribunales de amparo para que intervengan en su protección, puesto que el juicio de garantías es un medio de control jurisdiccional que se ejercita por vía de acción, de tal manera que las autoridades jurisdiccionales encargadas de conocer de él no pueden actuar oficiosamente, aun cuando tenga conocimiento de la existencia de una violación de garantías en perjuicio de persona determinada (Suprema Corte de Justicia de la Nación, 2012. p. 33).

Este principio se encuentra estatuido por los artículos 107, fracción I, de la Constitución General de la República y 6 de la Ley de Amparo, el cual señala que el juicio de garantías solo puede ser promovido por la parte a quien perjudique la ley, el tratado internacional, el reglamento o cualquier otro acto que se reclame; y únicamente podrá seguirse por el agraviado, por su representante legal o su defensor.

Finalmente, la Suprema Corte de Justicia menciona que el principio de iniciativa o de instancia de parte

...hace que el juicio jamás pueda operar oficiosamente y, por lo mismo, para que nazca sea indispensable que lo promueva alguien, principio que resulta obvio si se tiene en cuenta que el procedimiento de control, como juicio que es, sólo puede surgir a la vida jurídica por el ejercicio de la acción constitucional del gobernado, que ataca al acto autoritario que considera lesivo a sus derechos... (Chávez, 2013, p. 178).

Artículo 107. Todas las controversias de que habla el artículo 103 se sujetarán a los procedimientos y formas del orden jurídico que determine la ley, de acuerdo con las bases siguientes: 
El juicio de amparo se seguirá siempre a instancia de parte agraviada (...)

A mayor abundamiento el artículo 6 de la Ley de Amparo precisa lo siguiente:

Artículo 6o. El juicio de amparo puede promoverse por la persona física o moral a quien afecte la norma general o el acto reclamado en términos de la fracción I del artículo 5o. de esta Ley. El quejoso podrá hacerlo por sí, por su representante legal o por su apoderado, o por cualquier persona en los casos previstos en esta Ley.

Cuando el acto reclamado derive de un procedimiento penal, podrá promoverlo, además, por conducto de su defensor o de cualquier persona en los casos en que esta Ley lo permita (2013, p. 73).

La instancia de Parte Agraviada rige para todos los actos del proceso y no solo para la demanda.

\section{Principio de existencia de agravio personal y directo}

Este principio encuentra fundamento en los artículos 103 y 107, fracción I, de Constitución Federal, así como el 6 y 61, fracción XII, a contrario sensu.

Conforme a los citados preceptos, para que el juicio de garantías sea procedente es necesario que el acto de autoridad que se reclame efectivamente ocasione un agravio al quejoso, entendiéndose por agravio, para el efecto del juicio de amparo, según lo ha dispuesto el Máximo Tribunal, la ofensa o perjuicio que se hace a alguno, en sus derechos o intereses, tomándose la palabra "perjuicio", no en términos de la ley civil, como la privación de cualquier ganancia lícita que pudiera haberse obtenido, sino como sinónimo de ofensa que se hace a los derechos o intereses de una persona.

Por lo que, tomando en consideración que el acto reclamado es la fuente del agravio al quejoso y a su vez, el agravio es la base del interés jurídico en el amparo, ya que, en esencia, este es el derecho legítimamente tutelado, cuya violación faculta a su titular para demandar de la justicia federal el que se condene a la autoridad responsable a la restitución de la garantía individual violada.

Este principio tiene tres componentes:

a) El agravio:

b) Su calidad de personal; $y$,

c) Que sea directo (Romero, 2012, p. 154).

Literalmente el vocablo agravio tiene entre sus significados el de ofensa o perjuicio que se hace a alguien en sus derechos o intereses.

Es «personal» en la medida en que el perjuicio debe ser causado a una persona física o moral concreta, no abstracta, que se identifica como el titular del derecho transgredido.

Desde la perspectiva de nuestra materia, podríamos considerar que el agravio es directo si el acto de autoridad causa de manera inmediata un perjuicio al agraviado. 


\section{Principio de prosecución judicial}

Dicho principio versa en que el juicio de amparo se tramita por medio de procedimientos y formas de orden jurídico, esto revela que

la substanciación del mismo es un verdadero procedimiento judicial en el cual se observan las formas jurídicas procesales, implícitamente presupone que su tramitación suscita un verdadero debate o controversia entablados entre el promotor del amparo y la autoridad responsable, como las principales partes del juicio de amparo, en el que cada cual defiende sus respectivas pretensiones (Góngora, 2012, p. 154).

En efecto traduciéndose el ejercicio de amparo es una controversia surgida entre el agraviado y la autoridad responsable, sin sufrir desventaja el primero de ellos; esto es, el juicio se tramitará con arreglo, exclusivamente, a las disposiciones procesales de la Ley de Amparo y, solo en caso de que esta sea omisa o insuficiente, por supletoriedad se aplicará el Código Federal de Procedimientos Civiles.

\section{Principio de la relatividad de las sentencias}

Este principio es un efecto de la sentencia que concede el amparo y consiste en que esa sentencia solo habrá de beneficiar a quienes solicitaron la protección constitucional, es decir, no tiene efectos generales, más no a aquellos que por negligencia, falta de asesoría, situación económica o cualquier otra razón no impetraron la vía constitucional de amparo.

Fundamento constitucional Artículo. 107, fracción II:

La sentencia será siempre tal que sólo se ocupe de individuos particulares, limitándose a ampararlos y protegerlos en el caso especial sobre el que verse la queja, sin hacer una declaración general respecto de la ley o acto que la motivare.

Fundamento legal. Artículo 73 Ley de Amparo

Las sentencias que se pronuncien en los juicios de amparo sólo se ocuparán de los individuos particulares o de las personas morales, privadas u oficiales que lo hubieran solicitado, limitándose a ampararlos y protegerlos, si procediere, en el caso especial sobre el que verse la demanda, sin hacer una declaración general respecto de la ley o acto que la motive.

\section{Principio de definitividad}

El principio de definitividad que rige el juicio de garantías y el cual ordena que antes de promover el juicio de amparo se deben agotar todos los recursos ordinarios o medios de defensa legales que procedan contra el acto que se estime ilegal y que tengan el efecto de revocarlo, modificarlo o nulificarlo, ya que de lo contrario se actualizaría su improcedencia, en virtud a que en esta vía deberá acudirse solo cuando la actuación que se impugna no pueda remediarse ante las propias autoridades de instancia. 
Asimismo, existen casos de excepción al referido principio de definitividad, es decir, las hipótesis en que no será necesario agotar, previo a la promoción del juicio de amparo, los medios de impugnación ordinarios existentes, entre los cuales encontramos:

a) Cuando sean actos que importen peligro de privación de la vida, ataques a la libertad personal fuera de procedimiento, incomunicación, deportación o expulsión, proscripción o destierro, extradición, desaparición forzada de personas o alguno de los prohibidos por el artículo 22 de la Constitución Política de los Estados Unidos Mexicanos, así como la incorporación forzosa al Ejército, Armada o Fuerza Aérea nacionales;

b) Cuando el acto reclamado consista en órdenes de aprehensión o reaprehensión, autos de vinculación a proceso, resolución que niegue la libertad bajo caución o que establezca los requisitos para su disfrute, resolución que decida sobre el incidente de desvanecimiento de datos, orden de arresto o cualquier otro que afecte la libertad personal del quejoso, siempre que no se trate de sentencia definitiva en el proceso penal;

c) Cuando se trate de persona extraña al procedimiento.

d) No existe obligación de agotar tales recursos o medios de defensa, si el acto reclamado carece de fundamentación, cuando sólo se aleguen violaciones directas a la Constitución o cuando el recurso o medio de defensa se encuentre previsto en un reglamento sin que la ley aplicable contemple su existencia.

e) Si en el informe justificado la autoridad responsable señala la fundamentación y motivación del acto reclamado, operará la excepción al principio de definitividad (Góngora, 2004, p. 123).

\section{Principio de estricto derecho}

Conforme a este principio, el órgano de control constitucional, al resolver los juicios de amparo o recursos sometidos a su conocimiento debe limitarse a valorar las consideraciones expuestas por el quejoso o recurrente, sin atender a aspectos distintos, por lo que el juzgador no puede invocar vicios notorios de inconstitucionalidad que no haya hecho valer el quejoso (Góngora, 2004, p. 234).

En consecuencia, puede señalarse que, conforme a este principio el acto reclamado o resolución recurrida no pueden ser valorados libremente por el órgano de control constitucional, pues el examen que este realice debe limitarse a determinar si los conceptos de violación o agravios son o no fundados $\mathrm{y}$, por ende, si procede o no otorgar al gobernado la protección de la Justicia Federal, lo que implica que no está facultado para basar la inconstitucionalidad del acto reclamado o la ilegalidad de la resolución recurrida en una consideración no aducida por el quejoso o recurrente. 


\section{LA ACCIÓN DEL JUICIO DE AMPARO}

Consecuencia de la disposición del artículo 6 de la Ley Reglamentaria, de los artículos 103 y 107 de la Constitución Federal, en el sentido en que el juicio de amparo únicamente puede promoverse por la parte a quien perjudique el acto o la ley que se reclama, pudiendo hacerlo por sí, por su representante, etcétera; y que solo podrá seguirse por el agraviado, por su representante legal, entre otros, y por otra parte, del principio en el que a nadie puede obligarse a intentar o proseguir una acción contra su voluntad, sino en los casos especialmente previstos por la ley, es la, de que el desistimiento del recurso de revisión hecho por la parte que lo intentó motiva que el mismo se dé por terminado legalmente; quedando en pie en toda su fuerza ejecutoria como si no hubiera sido recurrida la resolución que constituye el acto reclamado en el caso concreto.

\section{Concepto de acción}

La acción procesal es el "poder jurídico que tiene todo sujeto de derecho, consistente en la facultad de acudir ante los órganos de jurisdicción, exponiendo sus pretensiones y formulando la petición que afirma como correspondiente a su derecho vulnerado" (Chávez, 2013, 154).

\section{La acción del juicio de amparo}

Carlos Arellano García conceptualiza la acción de amparo como

... derecho subjetivo de una persona física o moral, en su carácter de gobernada, para acudir ante el Poder Judicial de la Federación u órganos con competencia auxiliar, a exigir el desempeño de la función jurisdiccional, para obtener la tutela de una garantía individual o de un derecho derivado de la distribución de facultades entre Federación y Estados, presuntamente violados por una autoridad estatal responsable (Arellano, 2012, p. 408).

Si bien, todos los gobernados tienen derecho de ejercitar la acción de amparo, para que el juicio sea procedente, es indispensable que quien lo promueva sea la persona directamente agraviada por el acto de autoridad que se tilda de inconstitucional; es decir, quien tenga interés jurídico, pues, es un presupuesto indispensable en el examen de la controversia constitucional, la existencia del interés jurídico del quejoso.

\section{PARTES EN EL JUICIO DE AMPARO}

De acuerdo con el artículo 5 de la Ley de Amparo vigente, las partes en el juicio de amparo son: 
I. El quejoso, teniendo tal carácter quien aduce ser titular de un derecho subjetivo o de un interés legítimo individual o colectivo, siempre que alegue que la norma, acto u omisión reclamados violan los derechos previstos en el artículo 1 de la presente Ley y con ello se produzca una afectación real y actual a su esfera jurídica, ya sea de manera directa o en virtud de su especial situación frente al orden jurídico.

El interés simple en ningún caso podrá invocarse como interés legítimo. La autoridad pública no podrá invocar interés legítimo. El juicio de amparo podrá promoverse conjuntamente por dos o más quejosos cuando resientan una afectación común en sus derechos o intereses, aun en el supuesto de que dicha afectación derive de actos distintos, si estos les causan un perjuicio análogo y provienen de las mismas autoridades.

Tratándose de actos o resoluciones provenientes de tribunales judiciales, administrativos, agrarios o del trabajo, el quejoso deberá aducir ser titular de un derecho subjetivo que se afecte de manera personal y directa; la víctima u ofendido del delito podrán tener el carácter de quejosos en los términos de esta Ley.

II. La autoridad responsable, teniendo tal carácter, con independencia de su naturaleza formal, la que dicta, ordena, ejecuta o trata de ejecutar el acto que crea, modifica o extingue situaciones jurídicas en forma unilateral y obligatoria; u omita el acto que de realizarse crearía, modificaría o extinguiría dichas situaciones jurídicas.

Para los efectos de esta Ley, los particulares tendrán la calidad de autoridad responsable cuando realicen actos equivalentes a los de autoridad, que afecten derechos en los términos de esta fracción, y cuyas funciones estén determinadas por una norma general.

III. El tercero interesado, pudiendo tener tal carácter:

a) La persona que haya gestionado el acto reclamado o tenga interés jurídico en que subsista;

b) La contraparte del quejoso cuando el acto reclamado emane de un juicio o controversia del orden judicial, administrativo, agrario o del trabajo; o tratándose de persona extraña al procedimiento, la que tenga interés contrario al del quejoso;

c) La víctima del delito u ofendido, o quien tenga derecho a la reparación del daño o a reclamar la responsabilidad civil, cuando el acto reclamado emane de un juicio del orden penal y afecte de manera directa esa reparación o responsabilidad;

d) El indiciado o procesado cuando el acto reclamado sea el no ejercicio o el desistimiento de la acción penal por el Ministerio Público;

e) El Ministerio Público que haya intervenido en el procedimiento penal del cual derive el acto reclamado, siempre y cuando no tenga el carácter de autoridad responsable. 
IV. El Ministerio Público Federal en todos los juicios donde podrá interponer los recursos que señala esta Ley, y los existentes en amparos penales cuando se reclamen resoluciones de tribunales locales, independientemente de las obligaciones que la misma ley le precisa para procurar la pronta y expedita administración de justicia.

Sin embargo, en amparos indirectos en materias civil y mercantil, y con exclusión de la materia familiar, donde solo se afecten intereses particulares, el Ministerio Público Federal podrá interponer los recursos que esta Ley señala, solo cuando los quejosos hubieren impugnado la constitucionalidad de normas generales y este aspecto se aborde en la sentencia.

\section{Concepto de partes}

Existen diversas acepciones del concepto de partes, de acuerdo con el Manual del juicio de amparo, se entiende por partes:

Es quien reclama y frente a quien se reclama la satisfacción de una pretensión. En todo proceso, intervienen dos partes: una que pretende en nombre propio o en cuyo se pretende la actuación de una norma legal, denominada parte actora, y otra frente a la cual esa conducta es exigida, llamada demandada (Suprema Corte de Justicia, 2012, p. 234).

En específico en la materia de amparo, las partes son los sujetos de la relación jurídico-procesal en el juicio (Ley de Amparo).

\section{Quejoso}

El quejoso o agraviado es la persona física o moral que ejercita la acción del amparo para reclamar un acto de autoridad, lato sensu, que estima violatorio de sus garantías individuales o del sistema de distribución competencial existente entre la Federación y las entidades federativas; por lo tanto, puede considerarse al quejoso como la parte actora o demandante en el juicio de amparo, quien solicita la protección de la Justicia Federal.

El maestro Genaro Góngora Pimentel define al quejoso como:

Toda persona física o moral de derecho privado, o moral, oficial, que sufre una afectación por la ley o acto violatorio de sus derechos fundamentales por parte de una autoridad, o por la ley o acto de una autoridad federal que viole la soberanía local, o por la ley o actos de una autoridad local que vulnere o restrinja la soberanía federal $(2012$, p. 543).

Tienen el carácter de quejoso quien aduce ser titular de un derecho subjetivo o de un interés legítimo individual o colectivo, siempre que alegue que la norma, acto u omisión reclamados violan los derechos previstos en el artículo 1 de la Ley de 
Amparo, y con ello se produzca una afectación real y actual a su esfera jurídica, ya sea de manera directa o en virtud de su especial situación frente al orden jurídico.

El interés legítimo, se define como aquel interés personal, individual o colectivo, cualificado, actual, real y jurídicamente relevante, que puede traducirse, en caso de concederse el amparo, en un beneficio jurídico en favor del quejoso derivado de una afectación a su esfera jurídica en sentido amplio, que puede ser de índole económica, profesional, de salud pública, o de cualquier otra (tesis 1a. XLIII/2013 (10a.) 2a . Sala SCJN).

- El interés simple, en ningún caso, podrá invocarse como interés legítimo.

- La autoridad pública no podrá invocar interés legítimo.

El amparo colectivo, el juicio de amparo podrá promoverse conjuntamente por dos o más quejosos cuando resientan una afectación común en sus derechos o intereses, aun en el supuesto de que dicha afectación derive de actos distintos, si estos les causan un perjuicio análogo y provienen de las mismas autoridades.

\section{Autoridad responsable}

Es autoridad responsable la que dicta, promulga, publica, ordena, ejecuta o trata de ejecutar el acto reclamado u omite el acto que de realizarse crearía, modificaría o extinguiría situaciones jurídicas en forma unilateral y obligatoria.

La definición del concepto de autoridad responsable ha quedado a cargo de los tribunales federales, especialmente de la Suprema Corte de Justicia de la Nación, en su carácter de máximo intérprete de la Constitución General de la República.

Uno de los criterios más recientes que han sido sostenidos por el Alto Tribunal del País, con relación en las notas distintivas que definen a una autoridad para los efectos del juicio de amparo se encuentra plasmado en la jurisprudencia por contradicción de rubro y texto siguientes (2011, 2a./J.164/2011 9a época, 2a. Sala SCJN, S.J.F. y su gaceta, tomo XXXIV, septiembre de 2011, p. 1089):

AUTORIDAD PARA LOS EFECTOS DEL JUICIO DE AMPARO. NOTAS DISTINTIVAS. Las notas que distinguen a una autoridad para efectos del juicio de amparo son las siguientes: a) La existencia de un ente de hecho o de derecho que establece una relación de supra a subordinación con un particular; b) Que esa relación tenga su nacimiento en la ley, lo que dota al ente de una facultad administrativa, cuyo ejercicio es irrenunciable, al ser pública la fuente de esa potestad; c) Que con motivo de esa relación emita actos unilaterales a través de los cuales cree, modifique o extinga por sí o ante sí, situaciones jurídicas que afecten la esfera legal del particular; y, d) Que para emitir esos actos no requiera acudir a los órganos judiciales ni precise del consenso de la voluntad del afectado.

Como se ve del criterio obligatorio transcrito, las notas distintivas que debe reunir una autoridad para ser considerada como tal en el juicio de amparo son las siguientes:

a) La existencia de un ente de hecho o de derecho que establece una relación de supra a subordinación con un particular; 
b) Que la relación tenga su nacimiento en la norma legal que dota al ente de una facultad administrativa, cuyo ejercicio resulta irrenunciable, al ser de naturaleza pública la fuente de donde emana;

c) Que con motivo de esa relación emita u omita realizar actos unilaterales en los que cree, modifique o extinga, por sí o ante sí, situaciones jurídicas que afectan la esfera jurídica del particular; y

d) Que para emitir esos actos no requiera acudir a los órganos judiciales ni precisar del consenso de la voluntad del afectado.

Por lo que se concluye que, con independencia de su naturaleza formal, es la que dicta, ordena, ejecuta o trata de ejecutar el acto que crea, modifica o extingue situaciones jurídicas en forma unilateral y obligatoria; u omita el acto que de realizarse crearía, modificaría o extinguiría dichas situaciones jurídicas.

\section{Tercero interesado}

Es la persona física o moral que, sin ser actor o demandado participa en el juicio de amparo, y que la propia Ley de Amparo le reconoce el carácter de parte, por ser la persona que resulta beneficiada con el acto que el quejoso impugna en el juicio de amparo y que, por ende, tiene interés en que aquel subsista. En consecuencia persigue que se declare la constitucionalidad del acto reclamado por así convenir a sus intereses particulares, los cuales, por regla general, pueden estimarse coincidentes con las autoridades responsables.

\section{Ministerio Público}

En materia de amparo, el Ministerio Público de Federación, órgano de la Procuraduría General de la República, tiene como tarea fundamental fungir como la parte que tiene encomendada a la tutela del interés público, y está designado como parte en todos los juicios de amparo.

El Ministerio Público Federal sigue teniendo el carácter de parte en todos los juicios, donde podrá interponer los recursos necesarios, y los existentes en amparos penales cuando se reclamen resoluciones de tribunales locales.

\section{ACTOS CONTRA LOS CUALES PROCEDE EL JUICIO DE AMPARO INDIRECTO}

Primero es necesario señalar que el acto reclamado es la conducta imperativa, positiva u omisiva de una autoridad estatal nacional, federal, local o municipal, presuntamente violatoria de garantías individuales o de la distribución competencial establecida entre Federación y Estados de la República, a la que se opone el quejoso, actos de los cuales se realizó un listado de los mismos en la Ley de Amparo, establecido en el artículo 107 de la Ley en mención, entre los cuales señala: 
I. Contra normas generales que por su sola entrada en vigor o con motivo del primer acto de su aplicación causen perjuicio al quejoso.

Se entiende por normas generales, entre otras, las siguientes:

a) Los tratados internacionales aprobados en los términos previstos en el artículo 133 de la Constitución Política de los Estados Unidos Mexicanos; salvo aquellas disposiciones en que tales tratados reconozcan derechos humanos;

b) Las leyes federales;

c) Las constituciones de los Estados y el Estatuto de Gobierno del Distrito Federal;

d) Las leyes de los Estados y del Distrito Federal;

e) Los reglamentos federales;

f) Los reglamentos locales; y

g) Los decretos, acuerdos y todo tipo de resoluciones de observancia general;

II. Contra actos u omisiones que provengan de autoridades distintas de los tribunales judiciales, administrativos o del trabajo;

III. Contra actos, omisiones o resoluciones provenientes de un procedimiento administrativo seguido en forma de juicio, siempre que se trate de:

a) La resolución definitiva por violaciones cometidas en la misma resolución o durante el procedimiento si por virtud de estas últimas hubiere quedado sin defensa el quejoso, trascendiendo al resultado de la resolución; y

b) Actos en el procedimiento que sean de imposible reparación, entendiéndose por ellos los que afecten materialmente derechos sustantivos tutelados en la Constitución Política de los Estados Unidos Mexicanos y en los tratados internacionales de los que el Estado Mexicano sea parte;

IV. Contra actos de tribunales judiciales, administrativos, agrarios o del trabajo realizados fuera de juicio o después de concluido.

Si se trata de actos de ejecución de sentencia solo podrá promoverse el amparo contra la última resolución dictada en el procedimiento respectivo, entendida como aquella que aprueba o reconoce el cumplimiento total de lo sentenciado o declara la imposibilidad material o jurídica para darle cumplimiento, o las que ordenan el archivo definitivo del expediente, pudiendo reclamarse en la misma demanda las violaciones cometidas durante ese procedimiento que hubieren dejado sin defensa al quejoso y trascendido al resultado de la resolución.

En los procedimientos de remate la última resolución es aquella que en forma definitiva ordena el otorgamiento de la escritura de adjudicación y la entrega de los bienes rematados, en cuyo caso se harán valer las violaciones cometidas durante ese procedimiento en los términos del párrafo anterior; 
V. Contra actos en juicio cuyos efectos sean de imposible reparación, entendiéndose por ellos los que afecten materialmente derechos sustantivos tutelados en la Constitución Política de los Estados Unidos Mexicanos y en los tratados internacionales de los que el Estado mexicano sea parte;

VI. Contra actos dentro o fuera de juicio que afecten a personas extrañas;

VII. Contra las omisiones del Ministerio Público en la investigación de los delitos, así como las resoluciones de reserva, no ejercicio, desistimiento de la acción penal, o por suspensión de procedimiento cuando no esté satisfecha la reparación del daño; y

VIII. Contra actos de autoridad que determinen inhibir o declinar la competencia o el conocimiento de un asunto.

\section{Tribunales de la federación que conocen del Juicio de Amparo}

En términos del artículo 1 constitucional, los órganos competentes del Poder Judicial de la Federación para efectuar el control de los actos de autoridad que constitucional y legalmente les corresponde, y a través de esa función deban tutelar en su máxima expresión los derechos humanos, solo pueden actuar en el ámbito de su propia competencia, por lo que no pueden apartarse de la regulación que el derecho positivo interno (constitucional, legal y jurisprudencial) les impone, y desde una competencia reglada deben ser operadores jurídicos vigorosos para darle eficacia a esa protección de los derechos fundamentales, pero siempre conforme a la forma y términos en que se ha dispuesto el despliegue de sus atribuciones.

\section{SUPREMA CORTE DE JUSTICIA DE LA NACIÓN}

La Suprema Corte de Justicia de la Nación es el máximo tribunal de México y cabeza del Poder Judicial de la Federación. Le corresponde defender el orden establecido por la Constitución Política de los Estados Unidos Mexicanos, mantener el equilibrio entre los diversos poderes y órganos de gobierno, y solucionar, de modo definitivo, asuntos judiciales de gran relevancia social, a través de las resoluciones jurisdiccionales que dicta. Por lo anterior, y al tratarse del principal y más alto tribunal de naturaleza constitucional, no existe órgano ni autoridad que se encuentre por sobre ella o recurso judicial que pueda interponerse en contra de sus decisiones.

Conformada por once ministros, uno de ellos designado Presidente de la Suprema Corte de Justicia de la Nación (México) o simplemente «Ministro Presidente».

\section{Tribunales de Circuito}

Estos tribunales federales, que de acuerdo con el número de magistrados integrantes pueden ser unitarios o colegiados, están distribuidos en todo el territorio de la nación y asignados a ciertas zonas geográficas denominadas circuitos judiciales. 
Los magistrados de estos tribunales duran en su encargo seis años, entre ellos eligen un presidente. En la actualidad existen 32 circuitos judiciales, que abarcan el territorio de uno o dos estados mexicanos.

\section{Tribunal Colegiado de Circuito}

Los Tribunales Colegiados de Circuito se componen de 3 magistrados, uno de los cuales es su presidente. Además, cuentan con un secretario de acuerdos y del número de secretarios, actuarios y empleados se determina el presupuesto. Pueden estar especializados en una materia: (penal, administrativa, civil, mercantil o laboral); o conocer de todas ellas.

Es de competencia de los Tribunales Colegiados de Circuito: los juicios de amparo directo contra sentencias definitivas, laudos o contra resoluciones que pongan fin al juicio por violaciones cometidas en ellas o durante la secuela del procedimiento; los recursos que procedan contra los autos y resoluciones que pronuncien los jueces de Distrito, tribunales Unitarios de Circuito o el superior del Tribunal responsable; el recurso de queja; el recurso de revisión contra las sentencias pronunciadas en la audiencia constitucional por los jueces de Distrito, tribunales Unitarios de Circuito o por el superior del Tribunal responsable, y cuando se reclame un acuerdo de extradición dictado por el Poder Ejecutivo a petición de un gobierno extranjero, o cuando se trate de los casos en que el Pleno de la Suprema Corte de Justicia haya ejercitado la facultad prevista en el 6 párrafo del artículo 94 de la Constitución Política; los recursos de revisión de las leyes contra las resoluciones definitivas de los tribunales de lo contencioso-administrativo federales y del Distrito Federal; los conflictos de competencia que se susciten entre tribunales Unitarios de Circuito o jueces de Distrito de su jurisdicción en juicios de amparo; los impedimentos y excusas que en materia de amparo se susciten entre jueces de Distrito, y en cualquier materia entre los magistrados de los tribunales de Circuito; los recursos de reclamación; y los demás asuntos que expresamente les encomiende la ley o los acuerdos generales emitidos por la Suprema Corte (Ruiz, 2009, p. 156).

Para ser magistrado de un tribunal colegiado se requiere ser ciudadano por nacimiento en pleno ejercicio de sus derechos, mayor de treinta y cinco años al día de su nombramiento, gozar de buena reputación, no haber sido condenado por delitos intencionales, o con pena privativa de libertad mayor de un año, contar con título de licenciado en derecho y práctica profesional de mínimo cinco años. Deben retirarse al cumplir los setenta y cinco años de edad. Los magistrados duran en su encargo seis años y si son ratificados o promovidos se convierten en inamovibles hasta que cumplan la edad citada anteriormente.

\section{Tribunal Unitario de Circuito}

Se componen de un magistrado y del número de secretarios, actuarios y empleados que determina el presupuesto. 
Es de competencia judicial de los tribunales Unitarios de Circuito: los juicios de amparo promovidos contra actos de otros tribunales unitarios de circuito, que no constituyan sentencias definitivas; la apelación de los asuntos conocidos en primera instancia por los juzgados de Distrito; el recurso procesal de denegada apelación; la calificación de los impedimentos, excusas y recusaciones de los jueces de Distrito, excepto en los juicios de amparo; los conflictos de competencia entre los jueces de Distrito sujetos a su jurisdicción, excepto en los juicios de amparo; y los demás asuntos que les encomienden las leyes.

\section{Juzgado de Distrito}

Los juzgados de Distrito se componen de un juez y del número de secretarios, actuarios y empleados que determina el presupuesto. Son los tribunales de primera instancia del Poder Judicial de la Federación. Actúan como jueces de Primera Instancia en juicios Ordinarios Federales (Competencia concurrente).

Pueden estar especializados en determinadas materias (penal, administrativa, civil y del trabajo) o conocer de todas ellas.

Es de competencia de los juzgados de Distrito: los delitos del orden federal; los procedimientos de extradición, salvo lo que se disponga en los tratados internacionales; las autorizaciones para intervenir cualquier comunicación privada; las controversias que se susciten con motivo de la aplicación de las leyes federales en materia administrativa, civil y del trabajo; resolver los juicios de amparo indirecto en materia penal, administrativa, civil y del trabajo.

\section{REQUISITOS DE LA DEMANDA}

A manera de introducción, se estima conveniente precisar como bien lo hace el jurista Góngora Pimentel el concepto de demanda:

Mediante la demanda de amparo se ejercita la acción de amparo, exigiéndole al órgano judicial el amparo de la justicia federal, para que se restituya al gobernado en el pleno goce del derecho fundamental violado y se repongan las cosas al estado que tenían antes de la violación a la Constitución (2010, p. 421).

La demanda de amparo indirecto deberá formularse por escrito o por medios electrónicos de acuerdo con el artículo 108 en los casos que la Ley de Amparo lo autorice, en la que se expresará:

I. El nombre y domicilio del quejoso y del que promueve en su nombre, quien deberá acreditar su representación;

II. El nombre y domicilio del tercero interesado, y si no los conoce, manifestarlo así bajo protesta de decir verdad;

III. La autoridad o autoridades responsables. En caso de que se impugnen normas generales, el quejoso deberá señalar a los titulares de los órganos de Estado a los que la ley encomiende su promulgación. En el caso de 
las autoridades que hubieren intervenido en el refrendo del decreto promulgatorio de la ley o en su publicación, el quejoso deberá señalarlas con el carácter de autoridades responsables, únicamente cuando impugne sus actos por vicios propios;

IV. La norma general, acto u omisión que de cada autoridad se reclame;

V. Bajo protesta de decir verdad, los hechos o abstenciones que constituyan los antecedentes del acto reclamado o que sirvan de fundamento a los conceptos de violación;

VI. Los preceptos que, conforme al artículo 1 de esta Ley, contengan los derechos humanos y las garantías cuya violación se reclame;

VII. Si el amparo se promueve con fundamento en la fracción II del artículo 1 de esta Ley, deberá precisarse la facultad reservada a los estados u otorgada al Distrito Federal que haya sido invadida por la autoridad federal; si el amparo se promueve con apoyo en la fracción III de dicho artículo, se señalará el precepto de la Constitución General de la República que contenga la facultad de la autoridad federal que haya sido vulnerada o restringida; $y$

VIII. Los conceptos de violación.

Cuando se promueva el amparo en los términos del artículo 15 de la Ley de Amparo, bastará para que se dé trámite a la demanda, que se exprese:

- El acto reclamado;

- La autoridad que lo hubiere ordenado, si fuere posible;

- La autoridad que ejecute o trate de ejecutar el acto; y

- En su caso, el lugar en que se encuentre el quejoso.

En estos supuestos, la demanda podrá formularse por escrito, por comparecencia o por medios electrónicos. En este último caso no se requerirá de firma electrónica.

Con la demanda se exhibirán copias para cada una de las partes y dos para el incidente de suspensión, siempre que se pidiere y no tuviere que concederse de oficio. Esta exigencia no será necesaria en los casos que la demanda se presente en forma electrónica.

El órgano jurisdiccional de amparo, de oficio, mandará expedir las copias cuando el amparo se promueva por comparecencia, por vía telegráfica o por medios electrónicos, lo mismo que en asuntos del orden penal, laboral tratándose de los trabajadores, cuando se puedan afectar intereses de menores o incapaces, así como los derechos agrarios de los núcleos de población comunal o ejidal o de los ejidatarios o comuneros, así como cuando se trate de quienes por sus condiciones de pobreza o marginación se encuentren en clara desventaja social para emprender un juicio.

Por otra parte, la legislación de amparo también prevé la figura de la ampliación de la demanda, la que en palabras del jurista Raúl Chávez Castillo define como:

Acto por virtud del cual el quejoso formula un agregado a su demanda de amparo en cualquier parte de la misma, en dos casos: uno, cuando la autoridad responsable 
no haya rendido su informe con justificación y de esté dentro del término legal para pedir amparo; y otro, cuando del informe con justificación rendido por la autoridad responsable aparezcan otras autoridades responsables que intervengan en la ejecución de los actos reclamados (2013, p. 5).

La demanda podrá ampliarse cuando:

- No hayan transcurrido los plazos para su presentación.

- Con independencia de lo previsto en la fracción anterior, el quejoso tenga conocimiento de actos de autoridad que guarden estrecha relación con los actos reclamados en la demanda inicial. En este caso, la ampliación deberá presentarse dentro de los plazos previstos en el artículo 17 de la Ley de Amparo.

En el caso de la fracción II, la demanda podrá ampliarse dentro de los plazos referidos en este artículo, siempre que no se haya celebrado la audiencia constitucional o bien presentar una nueva demanda.

\section{JURISPRUDENCIA}

Se entiende por jurisprudencia a la doctrina establecida por los órganos judiciales del Estado (por lo general, el Tribunal Supremo o Tribunales Superiores de Justicia) que se repiten en más de una resolución. Esto significa que para conocer el contenido completo de las normas vigentes, hay que considerar cómo han sido aplicadas en el pasado. En otras palabras, la jurisprudencia es el conjunto de sentencias que han resuelto casos fundamentándose en ellas mismas.

Entre los múltiples conceptos de jurisprudencia encontramos que en el Diccionario Jurídico virtual, se define como:

La jurisprudencia es la interpretación de la ley, de observancia obligatoria, que emana de las ejecutorias que pronuncia la Suprema Corte de Justicia de la Nación funcionando en Pleno o en Salas, y por los Tribunales Colegiados de Circuito. Doctrinariamente la jurisprudencia puede ser confirmatoria de la ley, supletoria e interpretativa. Mediante la primera, las sentencias ratifican lo preceptuado por la ley; la supletoria colma los vacíos de la ley, creando una norma que la complementa; mientras que la interpretativa explica el sentido del precepto legal y pone de manifiesto el pensamiento del legislador. La jurisprudencia interpretativa está contemplada en el artículo 14 de la Constitución Federal, en tanto previene que en los juicios del orden civil la sentencia definitiva deberá ser conforme a la letra o a la interpretación jurídica de la ley; y la jurisprudencia tiene una función reguladora consistente en mantener la exacta observancia de la ley y unificar su interpretación, y como tal, es decir, en tanto constituye la interpretación de la ley, la jurisprudencia será válida mientras esté vigente la norma que interpreta (http://www.diccionariojuridico. $\mathrm{mx} /$ ?pag=vertermino\&id=126). 
En esa misma tesitura, los Tribunales Colegiados de Circuito sostienen, en relación al tema que se comenta, que:

Época: Novena Época

Registro: 183029

Instancia: Tribunales Colegiados de Circuito

Tipo de Tesis: Aislada

Fuente: Semanario Judicial de la Federación y su Gaceta Tomo XVIII, octubre de 2003 Materia(s): Común

Tesis: IX.10.71 K, página: 1039.

JURISPRUDENCIA. CONCEPTO, CLASES Y FINES. La jurisprudencia es la interpretación de la ley, de observancia obligatoria, que emana de las ejecutorias que pronuncia la Suprema Corte de Justicia de la Nación funcionando en Pleno o en Salas, y por los Tribunales Colegiados de Circuito. Doctrinariamente la jurisprudencia puede ser confirmatoria de la ley, supletoria e interpretativa. Mediante la primera, las sentencias ratifican lo preceptuado por la ley; la supletoria colma los vacíos de la ley, creando una norma que la complementa; mientras que la interpretativa explica el sentido del precepto legal y pone de manifiesto el pensamiento del legislador. La jurisprudencia interpretativa está contemplada en el artículo 14 de la Constitución Federal, en tanto previene que en los juicios del orden civil la sentencia definitiva deberá ser conforme a la letra o a la interpretación jurídica de la ley; y la jurisprudencia tiene una función reguladora consistente en mantener la exacta observancia de la ley y unificar su interpretación, y como tal, es decir, en tanto constituye la interpretación de la ley, la jurisprudencia será válida mientras esté vigente la norma que interpreta.

Amparo en revisión 299/2003. Funerales la Ascención, S.A. de C.V. 3 de julio de 2003. Unanimidad de votos.

Ponente: F. Guillermo Baltazar Alvear. Secretario: Esteban Oviedo Rangel.

El estudio de las variaciones de la jurisprudencia a lo largo del tiempo es la mejor manera de conocer las evoluciones en la aplicación de las leyes, quizás con mayor exactitud que el mero repaso de las distintas reformas del derecho positivo que en algunos casos no llegan a aplicarse realmente a pesar de su promulgación oficial.

En el derecho anglosajón es una fuente de importante magnitud, debido a que los jueces deben fundamentar sus decisiones o sentencias judiciales mediante un estudio minucioso de los precedentes, hechos o pruebas que incriminen al detenido sin violar o vulnerar sus principales derechos.

En el derecho continental, la jurisprudencia es también una fuente formal, aunque varía sustancialmente su valor y fuerza vinculante de acuerdo con las legislaciones locales de cada país. Es así que en algunos casos, los fallos de cierto tipo de tribunales superiores son de aplicación obligatoria para supuestos equivalentes en tribunales inferiores; en otros, las decisiones de instancias jurisdiccionales similares 
no son por lo regular vinculantes para jueces inferiores, excepto que se den ciertas circunstancias específicas a la hora de unificar criterios interpretativos uniformes sobre cuestiones determinadas en materia de derecho (como en el caso de las sentencias plenarias en el derecho argentino). Finalmente, y como alternativa más extendida en los Estados que ostentan estos sistemas jurídicos, puede que los fallos de nivel superior, en ningún supuesto resulten obligatorios para el resto de los tribunales, aunque sí suelen ostentar importante fuerza dogmática a la hora de predecir futuras decisiones y establecer los fundamentos de una petición determinada frente a los tribunales inferiores.

En todo caso, tampoco el estudio de las sentencias nos da la medida exacta de la realidad del Derecho porque ocurre que en ocasiones y por diversas razones las sentencias dejan de cumplirse o aplicarse.

Esto es así especialmente cuando el poder judicial entra en colisión con otros poderes del Estado moderno como el ejecutivo y el legislativo, y aunque compromete el principio de separación de poderes es un fenómeno que no puede desconocerse completamente al elaborar una teoría del Derecho, a riesgo de que aparezca como totalmente separada de la realidad jurídica y social.

La jurisprudencia se inspira en el propósito de obtener una interpretación uniforme del derecho en los casos que la realidad presenta a los jueces.

\section{Concepto de Jurisprudencia}

Son las interpretaciones que realizan las autoridades jurisdiccionales de los preceptos legales. La jurisprudencia se establece por reiteración de criterios, por contradicción de tesis y por sustitución.

a) Por reiteración se establece por la Suprema Corte de Justicia de la Nación, funcionando en pleno o en salas, o por los tribunales colegiados de circuito.

b) Por contradicción se establece por el pleno o las salas de la Suprema Corte de Justicia de la Nación y por los Plenos de Circuito.

Elaboración de la jurisprudencia, cuando la Suprema Corte de Justicia de la Nación, los plenos de Circuito o los tribunales colegiados de Circuito establezcan un criterio relevante, se elaborará la tesis respectiva, la cual deberá contener:

- El título que identifique el tema que se trata;

- El subtítulo que señale sintéticamente el criterio que se sustenta;

- Las consideraciones interpretativas mediante las cuales el órgano jurisdiccional haya establecido el criterio;

- Cuando el criterio se refiera a la interpretación de una norma, la identificación de esta; $y$

- Los datos de identificación del asunto, el número de tesis, el órgano jurisdiccional que la dictó y las votaciones emitidas al aprobar el asunto $\mathrm{y}$, en su caso, en relación con el criterio sustentado en la tesis. 
Además de los elementos señalados en las fracciones I, II, III y IV la jurisprudencia emitida por contradicción o sustitución deberá contener, según sea el caso, los datos de identificación de las tesis que contiendan en la contradicción o de la tesis que resulte sustituida, el órgano que las emitió, así como la votación emitida durante las sesiones en que tales contradicciones o sustituciones se resuelvan.

El pleno o las salas de la Suprema Corte de Justicia de la Nación, los plenos de circuito o los tribunales colegiados de circuito deberán remitir las tesis en el plazo de quince días a la dependencia de la Suprema Corte de Justicia de la Nación encargada del Semanario Judicial de la Federación, para su publicación.

En el Semanario Judicial de la Federación se publicarán las tesis que se reciban y se distribuirá en forma eficiente para facilitar su conocimiento.

Igualmente se publicarán las resoluciones necesarias para constituir, interrumpir o sustituir la jurisprudencia y los votos particulares. También se publicarán las resoluciones que los órganos jurisdiccionales competentes estimen pertinentes.

Cuando las partes invoquen tesis de jurisprudencia o precedentes expresarán los datos de identificación y publicación. De no haber sido publicadas, bastará que se acompañen copias certificadas de las resoluciones correspondientes.

\section{Obligatoriedad de la Jurisprudencia}

La jurisprudencia que establezca la Suprema Corte de Justicia de la Nación, funcionando en pleno o en salas, es obligatoria para éstas tratándose de la que decrete el pleno, y además para los plenos de circuito, los tribunales colegiados y unitarios de circuito, los juzgados de Distrito, tribunales militares y judiciales del orden común de los Estados y del Distrito Federal, y tribunales administrativos y del trabajo, locales o federales.

La jurisprudencia que establezcan los plenos de circuito es obligatoria para los tribunales colegiados y unitarios de circuito, los juzgados de distrito, tribunales militares y judiciales del orden común de las entidades federativas y tribunales administrativos y del trabajo, locales o federales que se ubiquen dentro del circuito correspondiente.

La jurisprudencia que establezcan los tribunales colegiados de circuito es obligatoria para los órganos mencionados en el párrafo anterior, con excepción de los plenos de circuito y de los demás tribunales colegiados de circuito.

La jurisprudencia en ningún caso tendrá efecto retroactivo en perjuicio de persona alguna. 


\section{ACUMULACIÓN Y SEPARACIÓN DE JUICIOS ANTES DE LA REFORMA A LA LEY DE AMPARO}

Para una mayor comprensión del tema objeto del presente estudio, se requiere el análisis de la figura procesal de la acumulación, la cual a contrario sensu dio fundamento legal al criterio jurisprudencial que permitía la procedencia de la separación de los juicios de amparo, es por ello que someramente se expondrán las principales nociones de dicha figura.

Primeramente, resulta necesario precisar que la acumulación es una figura procesal en amparo indirecto en la que dos juicios se acumulan por ser semejantes, se puede dar cuando dichos juicios estén en un mismo juzgado de Distrito o en otro diferente.

Las dudas se decidirán por el Tribunal Colegiado de Circuito dentro de cuya jurisdicción resida el juez de Distrito que previno, lo anterior con el fin de evitar el trámite de dos juicios que versarán sobre la anticonstitucionalidad del mismo acto reclamado y atiende al principio de economía procesal y evita que se emitan sentencias contradictorias al resolver el mismo acto reclamado, ya que con la acumulación solo se lleva un proceso y solo se emite una sola sentencia.

\section{Concepto de acumulación}

La acumulación consiste en engrosar dos o más juicios conexos y tiene como objetivo que estos se fallen en una misma sentencia para evitar resoluciones contradictorias.

El abrogado artículo 57, fracción II, de la Ley Orgánica del Juicio de Garantías disponía que podía decretarse la acumulación a instancia de parte o de oficio cuando se trate de juicios promovidos contra las mismas autoridades, por el mismo acto reclamado, siendo diversos los quejosos; por lo que esta disposición se consideraba aplicable para decretar la acumulación, teniendo en cuenta que tenía por objeto tanto la economía del procedimiento como evitar la contradicción de resoluciones que se dicten por diversos juzgadores en negocios que impliquen el mismo problema jurídico, si los actos reclamados son sustancialmente los mismos, y las autoridades responsables son también las mismas, y solo hay variedad en cuanto al número de las autoridades encargadas de ejecutar las órdenes reclamadas; de todo lo cual se desprende que existe conexidad en los juicios y es conveniente su acumulación.

\section{Procedencia de la acumulación}

La figura de la acumulación en el juicio de amparo se regulaba en el artículo 57 de la Ley de la materia abrogada, el cual preveía su procedencia, a instancia de parte o de oficio, en los siguientes casos: 
I. tratándose de dos juicios en los que el quejoso y el acto reclamado sean los mismos, aunque tanto las violaciones constitucionales como las autoridades sean diversas; $y$

II. cuando los sujetos pasivos y el acto reclamado sean los mismos en los juicios de amparo conexos, aunque los quejosos sean distintos.

Ahora bien, conforme a una interpretación literal de dicho precepto la acumulación resulta improcedente cuando los actos reclamados no sean iguales; sin embargo, para determinar respecto de su procedencia debe recurrirse al método de interpretación progresiva, toda vez que las normas jurídicas no pueden prever todas las situaciones posibles, para adaptarlas al presente en que se aplican. De manera que cuando se trate de actos reclamados que tiendan al mismo propósito, a guisa de ejemplo, la revisión del contrato colectivo, en uno la integral y en otro solo la salarial, se configura esta posibilidad, pues si bien no son iguales los actos, existe una íntima conexión entre ellos; lo anterior, a fin de evitar se dicten sentencias contradictorias y se hagan efectivos los principios de economía y concentración procesal.

\section{Tramitación del incidente de acumulación}

Si en un mismo juzgado se siguen juicios donde se pide acumulación, el juez dirá que se haga relación de ellos en una audiencia en la que se oirán los alegatos de las partes y se dictará la resolución que proceda, contra la cual no se admitirá recurso alguno.

Si los juicios se llevan en juzgados diferentes, promovida se citará a una audiencia en la que se oirán los alegatos que produjeren las partes y se dictará la resolución que corresponda.

Las partes que litiguen deberán conocer y dar a conocer el nombre del juez a quien se dirija el oficio para que expongan lo que a su derecho convenga en una audiencia en la que aquel resolverá sobre la procedencia o improcedencia de la acumulación.

Si se estima procedente la acumulación, se remitirán los autos al juez requirente con emplazamiento de las partes; y si se estima que no procede se comunicará sin demora al juez requirente, donde remitirán los autos de sus respectivos juicios, y una vez recibidos el Tribunal Colegiado de Circuito resolverá dentro del término de 8 días si procede o no la acumulación. Desde que se pida la acumulación hasta que se resuelva, se suspenderá todo procedimiento en los juicios de que se trate, hecha excepción de los incidentes de suspensión.

Cuando se haya resuelto la acumulación los amparos acumulados deberán decidirse en una sola audiencia teniéndose en cuenta todas sus constancias. Los juicios de amparo que se traten de competencia o acumulación deben ser designados competentes. 


\section{Fundamento legal de la tramitación del incidente de acumulación}

El fundamento legal del trámite del incidente de acumulación se encontraba previsto en la Ley de Amparo abrogada de 1936, en los artículos 27 a 63, los cuales a mayor abundamiento se citan:

Artículo 57. En los juicios de amparo que se encuentren en tramitación ante los jueces de Distrito, podrá decretarse la acumulación a instancia de parte o de oficio en los casos siguientes:

I. Cuando se trate de juicios promovidos por el mismo quejoso, por el mismo acto reclamado aunque las violaciones constitucionales sean distintas, siendo diversas las autoridades responsables.

II. Cuando se trate de juicios promovidos contra las mismas autoridades, por el mismo acto reclamado siendo diversos los quejosos, ya sea que éstos hayan intervenido en el negocio o controversia que motivó el amparo, o que sean extraños a los mismos.

Artículo 58. Para conocer de la acumulación, así como de los juicios acumulados, es competente el juez de Distrito que hubiere prevenido, y el juicio más reciente se acumulará al más antiguo.

Cualquier caso de duda o contienda sobre lo establecido en el párrafo anterior se decidirá por el Tribunal Colegiado de Circuito dentro de cuya jurisdicción resida el juez de Distrito que previno.

Artículo 59. Si en un mismo juzgado se siguen los juicios cuya acumulación se pide, _el juez dispondrá que se haga relación de ellos en una audiencia en la que se oirán los alegatos que produjeren las partes y se dictará la resolución que proceda, contra la cual no se admitirá recurso alguno.

Artículo 60. Si los juicios se siguen en juzgados diferentes, promovida la acumulación ante uno de ellos se citará a una audiencia en la que se oirán los alegatos que produjeren las partes y se dictará la resolución que corresponda.

Si el juez estima procedente la acumulación, reclamará los autos por medio de oficio, con inserción de las constancias que sean bastantes para dar a conocer la causa de la resolución.

El juez a quien se dirija el oficio lo hará conocer a las partes que ante él litiguen, para que expongan lo que a su derecho convenga en una audiencia en la que aquél resolverá sobre la procedencia o improcedencia de la acumulación.

Artículo 61. Si se estima procedente la acumulación, se remitirán los autos al juez requirente con emplazamiento de las partes.

Si se estima que no procede la acumulación, se comunicará sin demora al juez requirente, y ambos remitirán los autos de sus respectivos juicios, al Tribunal Colegiado de Circuito, dentro de cuya jurisdicción resida el juez de Distrito que previno. 
Recibidos los autos, con el pedimento del Ministerio Público Federal y los alegatos escritos que puedan presentar las partes, resolverá el Tribunal Colegiado de Circuito dentro del término de ocho días, si procede o no la acumulación y, además, qué juez debe conocer de los amparos acumulados.

Cuando la acumulación de juicios que se siguen en diferentes juzgados haya sido promovida por alguna de las partes y resulte improcedente, se impondrá a ésta una multa de treinta a ciento ochenta días de salario.

Artículo 62. Desde que se pida la acumulación hasta que se resuelva, se suspenderá todo procedimiento en los juicios de que se trate, hecha excepción de los incidentes de suspensión.

Artículo 63. Resuelta la acumulación, los amparos acumulados deberán decidirse en una sola audiencia teniéndose en cuenta todas las constancias de aquéllos.

Los autos dictados en los incidentes de suspensión relativos a los juicios acumulados se mantendrán en vigor hasta que se resuelva lo principal en definitiva, salvo el caso de que hubieren de reformarse por causa superveniente.

De la interpretación de los artículos 57 a 63 de la Ley de Amparo se advierte que en los juicios de garantías que se encuentren en trámite ante los jueces de Distrito podrá decretarse su acumulación, a instancia de parte o de oficio, en los casos que señala la ley; que será competente para conocer de la acumulación, así como de los juicios acumulados, el juez que hubiere prevenido, y que el más reciente se acumulará al más antiguo; que la acumulación podrá decretarse tanto respecto de los juicios de amparo que se sigan ante un mismo juzgado, como de los que se sigan ante juzgados diferentes; y que es potestativo para los jueces decretarla o no.

Ahora bien, como la facultad de decretar la acumulación de oficio se ejerce unilateralmente, con potestad plena y sin tramitación alguna, no es factible que un juez de Distrito pueda hacerlo respecto de juicios que se sigan ante otro juez, porque en esta hipótesis la acumulación ya no sería de oficio, sino mediante la necesaria concurrencia de dos voluntades, una que inicia el trámite sin poder vinculante y otra que accede a la acumulación y que no obraría por impulso propio ni a instancia de parte; luego, no es posible que, de oficio, un juez de Distrito le ordene a otro que esté conociendo de otros juicios de amparo, que le envíe los autos, porque este último está en libertad de negarse a hacerlo por virtud de la facultad discrecional de que goza.

En consecuencia, la acumulación de oficio solo puede ejercerse respecto de los juicios de amparo que se tramitan ante un mismo juzgado, mientras que la acumulación a instancia de parte podrá promoverse ante cualquiera de los jueces que estén conociendo de los juicios relacionados; sin embargo, en caso de que el que reciba la solicitud advierta de las constancias de autos que otro previno, conforme al sello fechador impreso en las demandas por la oficialía respectiva, deberá declararse legalmente incompetente para conocer del incidente de acumulación y remitir las constancias necesarias a aquel, a fin de que lo resuelva. 


\section{CONCEPTO DE SEPARACIÓN DE JUICIOS}

Es la figura procesal que aún no contemplada en la Ley de Amparo abrogada se encontraba vigente en los criterios jurisprudenciales, la cual consiste en como su nombre lo dice, separar de una demanda de amparo dos o más actos que no tengan una vinculación entre sí, por reclamar diferentes actos y distintas materias del derecho (civil, penal, mercantil, entre otras), o en su caso dos o más actos derivados de diferentes juicios o procedimientos, esto con el fin de evitar el dictado de una sentencia incongruente consigo misma, con la consecuente problemática que implicaría su cumplimiento y con ello no crear una incertidumbre jurídica y a su vez denegar justicia a quien acude a solicitar la protección de la Justicia Federal.

Lo anterior, desde luego, siempre y cuando los actos reclamados en la demanda tengan existencia autónoma y no dependan entre sí, es decir, que no sean consecuencia uno del otro, o que persigan el mismo objeto procesal, pues de resultar así, no debe decretarse la separación, en virtud de que no es factible dividir la continencia de la causa.

\section{PROCEDENCIA DE LA SEPARACIÓN DE JUICIOS DE AMPARO}

Si en una demanda de amparo se reclaman actos emanados de juicios diversos, desvinculados entre sí, y dicha demanda ha sido admitida por el juez de Distrito, o bien, tal circunstancia es advertida durante la tramitación del juicio (hasta antes de la celebración de la audiencia constitucional), con motivo de los informes justificados que rindan la o las autoridades responsables, se podía iniciar de oficio la separación de juicios, figura esta, que al no estar específicamente regulada en la Ley de Amparo, debía por ello quedar contenida en la jurisprudencia, tomando como base el artículo 57 de la Ley de Amparo, que establecía la acumulación, deduciéndolo en sentido contrario, por lo que puede concluirse que, fuera de los casos que ahí se prevén, en cualquier otro supuesto se requiere hacer la separación.

Por su parte, el Pleno de la Suprema Corte de Justicia de la Nación, en sus criterios jurisprudenciales, estableció que aun cuando la figura de "separación" no esté regulada específicamente por la Ley de Amparo, esta debe ser implementada aplicando en sentido contrario las disposiciones que regulan la acumulación de juicios precisadas por el artículo 57 de la Ley de Amparo.

Como ejemplo de lo anterior, cuando en una demanda de amparo directo formulada por diversos quejosos se reclaman, por una parte, actos relacionados con personas que intervinieron en el juicio natural y, por otra, actos vinculados con personas que se ostentan como extrañas al procedimiento, se decretaba la separación del juicio de garantías ante la imposibilidad de decidir en el amparo directo si se respetó o no la garantía de audiencia de las personas extrañas al procedimiento natural, toda vez que de acuerdo con lo previsto en los artículos 107, fracción V, de la 
Constitución General de la República y 158 de la Ley de Amparo, el juicio de garantías uniinstancial solamente procede contra sentencias definitivas, laudos o resoluciones que pongan fin al juicio, dictados por tribunales judiciales, administrativos o del trabajo, respecto de los cuales no proceda algún recurso ordinario mediante el cual puedan ser modificados o revocados, ya sea que la violación se cometa en dichas sentencias o que cometida durante el procedimiento afecten las defensas del quejoso, trascendiendo al resultado del fallo, lo que implica que el juicio de amparo directo solo puede promoverlo quien fue parte y se le escuchó en su defensa.

En cambio, para las personas extrañas al juicio natural del que emanen los actos reclamados, está reservado el juicio de amparo indirecto, en términos del artículo 114, fracción V, de la Ley de Amparo, el cual establece que debe ejercitarse la acción constitucional dentro del plazo legal correspondiente, porque es el procedimiento a través del cual la persona extraña puede ofrecer pruebas en la audiencia respectiva y, en caso de concederse la protección constitucional, puede determinarse que el acto reclamado no se ejecute en su contra hasta en tanto sea oída en su defensa, en respeto de su garantía de audiencia; por consiguiente, si los actos que se reclaman por los promoventes de una misma demanda de amparo directo deben tramitarse en vías diferentes en razón de su propia naturaleza, procede decretar la separación de juicios, aplicando en sentido contrario las reglas de la acumulación.

Asimismo, resulta procedente dicha separación cuando del texto de la demanda de amparo se advirtiera que se reclamaban actos provenientes de diversos juicios, con la finalidad de evitar el dictado de una sentencia incongruente consigo misma, con la consecuente problemática que implicaría su cumplimiento. Pues con ello se crearía una certidumbre jurídica y se evitaría a su vez denegar justicia a quien acude a solicitar la protección de la Justicia Federal.

De manera ilustrativa, se tiene el caso de que cuando de la demanda de garantías se advierta que se cuestiona la constitucionalidad de actos cuya competencia corresponda, por ejemplo, tanto a un juez de Distrito como a un Tribunal Colegiado, debe decretarse la separación de juicios, para que se evite el dictado de una sentencia respecto de un acto que legalmente no le compete conocer y a su vez, se dé oportunidad al quejoso para que pueda acreditar mediante pruebas, la inconstitucionalidad de los actos que reclama y que son propios del conocimiento del Juez de Distrito, esto es, cuando se reclama una resolución que pone fin a un procedimiento seguido en forma de juicio ante el cual no existe medio ordinario de defensa en su contra y, a su vez, se cuestiona un acto proveniente de una autoridad diversa de un tribunal judicial, administrativo o del trabajo en términos de la fracción II del artículo 114 de la Ley de Amparo; toda vez que no debe soslayarse que solo en el amparo indirecto se permite el ofrecimiento y admisión de pruebas tendentes a demostrar la inconstitucionalidad de los actos reclamados, mientras que en el amparo directo el acto debe ser analizado tal y como fue probado ante la responsable. 


\section{TRAMITACIÓN DE LA SEPARACIÓN DE JUICIOS DE AMPARO}

La separación de juicios podrá válidamente hacerse de oficio en cualquier estado del procedimiento, desde la etapa de la admisión de la demanda hasta antes de la celebración de la audiencia constitucional. El trámite deberá ser incidental, aplicando, en lo pertinente, los preceptos legales de la Ley de Amparo relativos a la acumulación, en sentido contrario, con suspensión del procedimiento principal, como lo establece el artículo 62 de dicha Ley, con audiencia de las partes y resolución que decrete la separación. El juez, en esta etapa, podrá hacer los requerimientos necesarios a las partes, aplicando por analogía lo dispuesto en el artículo 78 de la Ley de la materia, para conocimiento pleno de lo que resolverá.

\section{SUSTENTO JURISPRUDENCIAL PARA LA PROCEDENCIA DE LA SEPARACIÓN DE JUICIOS DE AMPARO}

El criterio de jurisprudencia que da fundamento a la figura procesal de la separación de juicios de amparo, se sustenta en la contradicción de tesis 8/94, entre las sustentadas por el Segundo Tribunal Colegiado del Décimo Séptimo Circuito y el Primer Tribunal Colegiado del Quinto Circuito, la cual fue estudio del pleno de la Suprema Corte de Justicia de la Nación, y establecido el criterio, de que si en una demanda de amparo se reclaman actos emanados de juicios diversos, desvinculados entre sí, no debe desecharse por notoriamente improcedente, al no existir causa expresa en la Ley de Amparo que así lo establezca; sin embargo, pudiera suceder que el órgano jurisdiccional que conoce del amparo ya hubiera dado entrada a la demanda de garantías, o bien que tal circunstancia surja durante la tramitación del juicio, con motivo de los informes justificados que rindan la o las autoridades responsables. En este evento, debe decirse que así como la Ley de Amparo regula la acumulación de juicios en las disposiciones legales transcritas, es necesario el que se haga una separación de juicios, ya que si bien esta figura no se encuentra regulada de manera específica en dicha ley, el caso es que debe ser incorporada a través de la jurisprudencia.

Por lo que, la anterior conclusión indujo a una serie de cuestionamientos: cómo, cuándo y en qué casos procede la separación de juicios, esto, sin duda, será posible en todos aquellos casos que no estén contenidos en las dos fracciones que, para la procedencia de la acumulación de juicios, establecía el artículo 57 de la Ley de Amparo abrogada, cuando el juez de Distrito se percate, ya durante el trámite del juicio y hasta antes de la celebración de la audiencia constitucional, de la existencia de los supuestos para esa separación, lo que implicaría que en tal situación deberá iniciar su trámite, deduciéndolo a contrario sensu de lo que establece el precepto legal citado.

Dicha separación de juicios podrá válidamente hacerse de oficio en cualquier estado del procedimiento, desde la etapa de la admisión de la demanda hasta antes de 
la celebración de la audiencia constitucional; el trámite deberá ser incidental aplicando, en lo pertinente, los artículos referentes a la acumulación a contrario sensu, con suspensión del procedimiento principal, como lo establece el artículo 62 de la Ley de Amparo, con audiencia de las partes y resolución que decrete la separación.

El juez, en esta etapa, podrá hacer los requerimientos necesarios a las partes y a las responsables, aplicándose, por analogía, lo dispuesto en el artículo 78 de la Ley de Amparo, para conocimiento pleno de lo que resolverá el juez.

Al decretarse la separación, el juez proveerá automáticamente la formación de los expedientes que en derecho resultan, registrándolos y engrosándolos con las copias certificadas que sean necesarias para su integración. Integrados los diferentes expedientes, el juez ordenará el trato que a cada uno corresponda jurídicamente: Si todos son de su competencia, los fallará por cuerda separada, si uno de ellos es competencia de otro órgano, sea de la Suprema Corte, del Tribunal Colegiado o de otro juez de Distrito, se dará el trámite correspondiente.

Por lo que la Suprema Corte de Justicia estimó que con lo anterior, en gran medida, se logrará una tramitación más transparente en los juicios de garantías, que en lo futuro evitaría el pronunciamiento de fallos complicados y tal vez confusos en su comprensión, no solo para los efectos de las sentencias que, en su caso, se pronuncien, concediendo el amparo y su cumplimiento, sino en el trámite de las impugnaciones que al respecto lleguen a formularse.

Todo lo antes mencionado responde, también, a que los tribunales de amparo, por los objetivos que se persiguen, traten de acatar las medidas propuestas, en aras de una adecuada administración de justicia, sirviendo de apoyo al respecto, en lo conducente, el artículo 57 de la Ley de Amparo, aplicado a contrario sensu, pues si bien alude a la acumulación de juicios de amparo, la separación de estos se impone, en la hipótesis que se analiza, precisamente porque si los actos reclamados en un solo asunto derivan de juicios o procesos diversos, desvinculados entre sí, nunca podrán darse los supuestos de acumulación que establece el último numeral citado, que requieren, como base fundamental, que se trate del mismo acto reclamado, lo que no acontece en la especie.

En la tesitura apuntada, se consideró que el criterio que debía prevalecer es el sostenido en dicha resolución por el más alto tribunal:

Época: Novena Época

Registro: 197671

Instancia: Pleno

Tipo de Tesis: Jurisprudencia

Fuente: Semanario Judicial de la Federación y su Gaceta

Tomo VI, Septiembre de 1997

Materia(s): Común

Tesis: P./J. 76/97

Página: 118 
SEPARACIÓN DE JUICIOS. SU PROCEDENCIA. Si en una demanda de amparo se reclaman actos emanados de juicios diversos, desvinculados entre sí, y dicha demanda ha sido admitida por el Juez de Distrito, o bien, tal circunstancia es advertida durante la tramitación del juicio (hasta antes de la celebración de la audiencia constitucional), con motivo de los informes justificados que rindan la o las autoridades responsables, podría iniciarse de oficio la separación de juicios, figura ésta, que al no estar específicamente regulada en la Ley de Amparo, debe por ello quedar contenida en la jurisprudencia, tomando como base el artículo 57 de esa ley, que establece la acumulación, deduciéndolo en sentido contrario, por lo que puede concluirse que, fuera de los casos que ahí se prevén, en cualquier otro supuesto se requiere hacer la separación.

\section{NUEVA REFORMA A LA LEY DE AMPARO, PUBLICADA EN EL DIARIO OFICIAL DE LA FEDERACIÓN EL 2 DE ABRIL DE 2013}

En los primeros días de junio de 2011, el 6 y el 10, se aprobaron dos reformas constitucionales de singular trascendencia, no solo para el país, sino en especial para el Poder Judicial de la Federación. La Reforma Constitucional en Materia de Amparo y la Reforma Constitucional en Materia de Derechos Humanos, concomitantes y fundamentales para el desarrollo integral del ciudadano en un régimen democrático. En esta última, se antepone a la "condición política de ciudadano", con derechos y obligaciones, la condición primigenia de "ser humano", y se ve reflejada en el "Capítulo I", del "Título Primero" de la Constitución Política de los Estados Unidos Mexicanos que ahora se denomina "De los Derechos Humanos y sus Garantías".

En lo que interesa respecto a la reforma en materia de amparo, el proceso de creación de una nueva Ley de Amparo concluyó el 2 de abril de 2013 con la publicación en el Diario Oficial de la Federación del Decreto que contiene la nueva redacción del texto reglamentario de los artículos 103 y 107 de la Constitución Política de los Estados Unidos Mexicanos, así como de las modificaciones a cinco leyes secundarias, que en conjunto habilitan competencias y posibilitan la aplicación de las nuevas disposiciones.

Entre los aspectos más importantes que es necesario conocer respecto a la Reforma Constitucional en Materia de Amparo, se derogaron los artículos 57, 58, 59, 60, 61, 62, 63, 64 y 65 de la Ley de Amparo, en los cuales se fundamentaba la figura procesal de la acumulación de los juicios de amparo, y como consecuencia el fundamento legal que servía de base, aplicado a contrario sensu a la jurisprudencia que establece la procedencia de la separación de juicio en materia de amparo, figura procesal objeto del presente estudio, la cual como ya se dijo a lo largo del desarrollo del presente trabajo de investigación, resultaba aplicable en los casos en que, en una demanda de amparo se reclamen actos emanados de juicios diversos, desvinculados entre sí, y dicha demanda ha sido admitida por el juez de Distrito, o bien, tal circunstancia es advertida durante la tramitación del juicio (hasta antes de la 
celebración de la audiencia constitucional), con motivo de los informes justificados que rindan la o las autoridades responsables, con el fin de separar los actos que no guardaren relación entre sí en una misma demanda de amparo, y con este nuevo acto aperturar un diverso juicio de garantías, radicado en el mismo órgano jurisdiccional que resolviera por cuenta separada el asunto, evitando con ello sentencias engorrosas, extensas, de difícil comprensión e incongruente consigo misma, evitando así incertidumbre jurídica.

Por lo anterior, resultaba beneficiosa la figura procesal de la separación de juicios en materia de amparo, toda vez que si no se encontraba prevista en la ley, se fundamenta en los preceptos que contemplaban la acumulación, máxime que se contraponía con el espíritu de Ley de Amparo.

En tal circunstancia, al publicarse la nueva Ley de Amparo el 2 de abril de 2013, trajo como consecuencia la inaplicabilidad de la jurisprudencia que sustentaba la separación de juicios al poder aplicar a contrario sentido la norma que preveía la acumulación al estar derogada.

\section{Impacto en la tramitación e integración del juicio de amparo}

Una vez señalado en qué consiste el amparo en México, estudiado las figuras procesales en las que se advierte la ventaja de algunas de estas en el juicio de amparo, como lo era la separación de juicio, figura que se suscitaba cuando del texto de la demanda de amparo se advierta que el quejoso reclamaba actos provenientes de diversos juicios, de diferentes materias, o en su caso durante la tramitación del juicio al momento de rendir los informes justificados a las autoridades responsables, se advertía una pluralidad de actos distintos entre sí sin guardar ninguna relación.

En tal circunstancia, se podía iniciar en vía incidental la separación de juicio con el fin de evitar el dictado de una sentencia incongruente consigo misma, con la consecuente problemática que implicaría su cumplimiento; lo anterior, fundamentado en la jurisprudencia número P./J. 76/97, sustentada por el pleno de la Suprema Corte de Justicia de la Nación, visible en la página 118, del tomo VI, correspondiente al mes de septiembre de 1997, publicada en el Semanario Judicial de la Federación y su Gaceta, Novena Época, la cual servía de base a la multicitada separación de juicios en materia de amparo, criterio que emanó en virtud de que en la práctica de la tramitación de los juicios de amparo, se promovían demandas con pluralidad de actos que no guardan relación entre sí, la única similitud era la persona que los promovía, lo cual dio origen al referido criterio jurisprudencial al no encontrarse previsto en la Ley de Amparo; establecida con el objetivo de crear certidumbre jurídica y eliminar denegación justicia pronta y expedita a quien acude a solicitar la protección de la Justicia Federal.

Así como para que se evite el dictado de una sentencia respecto de un acto que legalmente no le compete conocer, en los casos en que se planteé demanda de garantías de la cual advierta que se cuestiona la constitucionalidad de actos cuya competencia corresponda, tanto a un juez de Distrito como a un Tribunal Colegiado. 
Esta separación de juicios, daba oportunidad al quejoso para que pudiera acreditar mediante pruebas, la inconstitucionalidad de los actos que reclama y que son propios del conocimiento del juez de Distrito, esto es, cuando se reclama una resolución que pone fin a un procedimiento seguido en forma de juicio ante el cual no existe medio ordinario de defensa en su contra y, a su vez, se cuestiona un acto proveniente de una autoridad diversa de un tribunal judicial, administrativo o del trabajo; toda vez que no debe soslayarse que solo en el amparo indirecto se permite el ofrecimiento y admisión de pruebas tendentes a demostrar la inconstitucionalidad de los actos reclamados, mientras que en el amparo directo el acto debe ser analizado tal y como fue probado ante la responsable.

Lo anterior, desde luego, siempre y cuando los actos reclamados en la demanda tengan existencia autónoma y no dependan entre sí, es decir, que no sean consecuencia uno del otro, o que persigan el mismo objeto procesal, pues de resultar así, no debe decretarse la separación, en virtud de que no es factible dividir la continencia de la causa.

Por lo que, con la reforma a la ley de amparo publicada el 2 de abril de 2013, en el Diario Oficial de la Federación, se derogaron los artículos relativos a la acumulación en el juicio de amparo y como consecuencia la separación de juicios, que se encontraba fundamentada en criterio jurisprudencial a su vez sustentado en el artículo 57 de la Ley de Amparo, aplicado a contrario sensu.

Sin embargo, es de considerar que si bien no existe un impedimento material para efectuar un examen de los actos reclamados en un solo juicio de amparo, sin importar que entre ellos no haya conexidad, no significa que tal estudio debe hacerse, porque el impedimento es de orden jurídico y tiene su apoyo legal en el artículo en que se señalan los casos de acumulación. Sostener lo contrario llevaría al absurdo de que en un solo juicio, por la mera circunstancia de que se tratara de un solo quejoso, se analizaran actos desvinculados, de naturaleza tan disímbola, como pudieran ser actos provenientes de autoridades civiles, penales, administrativas e, incluso, de fueros diversos, lo que desde luego no es aceptable.

\section{Derogación de la acumulación en la nueva Ley de Amparo}

No es de negarse que en la buena voluntad del legislador, fue el llenar las lagunas y deficiencias que contaba la ley de amparo abrogada, toda vez que con el pasar de los años y con la evolución social se debe actualizar las leyes que rigen a la sociedad, y progresar a la par, para un mejor derecho subjetivo, sin embargo, en la exhaustiva reforma no meditaron la trascendencia de los fundamentos legales que la Ley de Amparo colateralmente preveía, para una mejor tramitación en la práctica de los juicios de amparo, por lo que, al derogar la figura procesal de la acumulación de los juicios de amparo contemplada en los numerales 57, 58, 59, 60, 61, 62, 63, 64 y 65 de la Ley de Amparo, afectaron a la diversa figura de la separación de juicios que tenía su fundamento jurisprudencial sustentado por la Suprema Corte de Justicia de la Nación, en el artículo 57 de la Ley Agraria, aplicado a contrario sentido. 
Por ello, lamentablemente, el juicio de amparo tendrá que atender a la ley supletoria civil para buscar fundamentos en los casos en los que surja la igualdad de actos y partes en los juicios de garantías, para evitar el dictado de sentencias contradictorias, lo cual es un paso atrás en la evolución de la justicia pronta y expedita, toda vez que la figura procesal de la acumulación se considera de suma relevancia a las finalidades de economía procesal y evita sentencias contradictorias; misma que con la reforma ya no se considera parte del sistema procesal del amparo.

\section{Desventajas de la nueva reforma a la Ley de Amparo}

Como ya se ha hecho notar, en lo que interesa la principal desventaja de la Ley de Amparo en vigor es la derogación de los artículos que contemplaban la acumulación del juicio de amparo, y colateralmente, pero con suma importancia, el fundamento que sostenía a la jurisprudencia que daba lugar a la separación de juicios, figura que a estas líneas ya se ha hecho notar que consiste en la separación de los actos que no guardan relación entre sí, en una misma demanda de amparo y como consecuencia sin dejar en estado de indefensión al gobernado, se apertura un diverso juicio de garantías con este nuevo acto, con el fin de evitar sentencia incongruentes y extensas que dificulten en el caso de otorgarse el amparo y protección de la justicia de la unión, el cumplimiento de las ejecutorias de amparo, máxime que por técnica jurídica iría en contra de la certeza jurídica y principio de celeridad.

Lo cual iría en contra del principio de justicia pronta y expedita, toda vez que nuestra Constitución Política de los Estados Unidos Mexicanos (2014) señala en su artículo 17, que:

Artículo 17. Ninguna persona podrá hacerse justicia por sí misma, ni ejercer violencia para reclamar su derecho.

Toda persona tiene derecho a que se le administre justicia por tribunales que estarán expeditos para impartirla en los plazos y términos que fijen las leyes, emitiendo sus resoluciones de manera pronta, completa e imparcial. Su servicio será gratuito, quedando, en consecuencia, prohibidas las costas judiciales.

Aunado a lo anterior, el legislador inobservo que las abrogaciones en material de acumulación en la Ley de Amparo contravenían disposiciones jurisprudenciales que regulaban la legalidad de las sentencias, conforme a los criterios que en materia de revisión aplicaban los tribunales colegiados en el estudio de las sentencias emitidas por los juzgados de Distrito, como se advierte del criterio sustentado por el Cuarto Tribunal Colegiado del Décimo Séptimo Circuito, que se cita:

Época: Novena Época

Registro: 186115

Instancia: Tribunales Colegiados de Circuito

Tipo de Tesis: Aislada

Fuente: Semanario Judicial de la Federación y su Gaceta 
Tomo XVI, Agosto de 2002

Materia(s): Común

Tesis: XVII.4o.8 K

Página: 1387

SEPARACIÓN DE JUICIOS. EL TRIBUNAL REVISOR PUEDE ORDENARLA DECRETANDO LA REPOSICIÓN DEL PROCEDIMIENTO, SI FUE OMISO EL A QUO EN EFECTUARLA. Técnicamente no resulta válido que en un solo juicio de amparo puedan ser analizados y resueltos actos reclamados pertenecientes a dos tipos de juicios autónomos y distintos entre sí, en acatamiento obligatorio a la jurisprudencia por contradicción número 77/97, sustentada por el Pleno de la Suprema Corte de Justicia de la Nación, publicada en la página 118, tomo VI, septiembre de 1997, de la Novena Época del Semanario Judicial de la Federación y su Gaceta, de rubro: «SEPARACIÓN DE JUICIOS. REGLAS PARA SU TRAMITACIÓN EN EL JUICIO DE GARANTÍAS». toda vez que el tribunal superior, que en el recurso de revisión asume la jurisdicción original en el juicio de amparo indirecto, debe ordenar que se subsane la violación a las normas fundamentales que rigen el procedimiento en el juicio de amparo, tal y como lo prevé el artículo 91, fracción IV, de la ley de la materia y ordenar la separación del procedimiento para tal efecto.

En tales circunstancias, resulta evidente la afectación en el trámite del juicio de amparo con la abrogación de los artículos que contemplaba la acumulación, pues no solo derogó dicha figura procesal, sino también las que se sustentaban legalmente, con dichos preceptos y con aportación benéfica a la tramitación del mismo.

\section{Propuesta de integración de la separación de juicios a la Ley de Amparo vigente}

Ahora bien, en atención a todo lo expuesto en el presente estudio, resulta procedente y apoyada en los criterios jurisprudenciales obtenidos con anterioridad a la reforma, la integración de la figura procesal de la separación de juicios de amparo en la actual legislación de amparo, toda vez que dicha institución, es de suma relevancia para la eficiente tramitación de los juicios de amparo; en virtud de que la aplicación de dicha figura procesal brinda una diversidad de beneficios al juicio de amparo, tanto en la tramitación como en el aspecto jurídico, por lo que, al no contraponerse con las disposiciones que establece la nueva Ley de Amparo publicada el 2 de abril de 2013, resulta procedente la integración de la misma en el cuerpo normativo de la Ley de Ampro, porque con ello el juzgador estará en posibilidad de dar solución adecuada al conflicto que se le ha planteado, salvaguardando así el derecho fundamental del gobernado a la impartición de justicia completa, pronta e imparcial.

Separación que se llevará a cabo, al momento de la admisión de la demanda o en su caso antes de celebrada la audiencia constitucional, vía incidental. 


\section{Beneficios de la integración de la separación de juicios a la Ley de Amparo vigente}

En relación con los beneficios que conllevarían la integración de la figura procesal de la separación de juicios de amparo a la ley de la materia, por no ir en contra de ninguno de sus preceptos, resulta indispensable señalar todos y cada uno de ellos, ya que los mismos nos dan la noción de la factibilidad que sería tener la multicitada figura procesal vigente en nuestro ordenamiento de amparo, por lo que a continuación, se precisan:

- Evitar el dictado de una sentencia incongruente consigo misma; en virtud de que al llevar a cabo la separación de los actos reclamados que no guardan relación entre sí en una misma demanda de amparo, el juzgador, al dictado de la sentencia solo tendrá que entrar al estudio de un acto reclamado el cual será analizado de forma única, con lo cual no generaría confusión a las partes al no ser tan extensa y engorrosa, ya que solo se acotaría únicamente a estudiar un acto reclamado. Evitar con la consecuente problemática que implicaría su cumplimiento en caso se sentencias concesorias del amparo; esto es, considerando en el caso que no se diera la separación de juicios en comento, y se entrará al estudio de dos actos diferentes en una sentencia y respecto de ambos se concediera el amparo y protección de la justicia de la unión, y respecto de una de las concesiones del amparo la parte tercera interesada interpusiera recurso de revisión, lo cual no permitiría que respecto del diverso acto del cual no se informó quedara firme la sentencia al remitirse el original del juicio de amparo al Tribunal Colegiado que por razón de turno correspondiera, toda vez que se tendría que estar en espera de la ejecutoria dictada por la superioridad, para que la misma quedara firme y proceder con la ejecución de la sentencia amparadora que haya sido confirmada o intocada; como esta hipótesis surgen muchas más en materia de cumplimiento, las cuales se advierten en la tramitación de los juicios de amparo en los diferentes órganos jurisdiccionales.

- Genera certidumbre jurídica, ello es así, porque al entrar al estudio de un solo acto reclamado el cual se analizará de forma exhaustiva en la sentencia, sin interrumpir la exposición de motivos y fundamentos, da lugar a una mejor prensión del tema sin generar una engorrosa y extensa sentencia que contenga el análisis de un diverso acto reclamado que no guarda relación en ningún aspecto.

- Elimina denegación justicia pronta y expedita a quien acude a solicitar la protección de la Justicia Federal, toda vez que con la separación de juicios las partes se limitan a las que tienen interés real en la litis del juicio de amparo, lo cual da una celeridad a la integración del juicio de amparo, toda vez que se evita el emplazamiento a personas que realmente no tengan el carácter de terceros al no tener vinculación con el acto que se reclama en el caso de que los actos no deriven del mismo procedimiento $o$ incluso en diferente materia. 
Un ejemplo de lo anterior, se da en el caso de que en una demanda de amparo en materia penal se reclame una orden de aprehensión a dos autoridades jurisdiccionales y al momento de rendir sus respectivos informes justificados informen la existencia de dos causas penales en las cuales se giró respectivamente, orden de aprehensión en contra del quejoso, y no se realice la separación en comento, por tanto, se tendría que seguir la tramitación del juicio de garantías por las dos órdenes y emplazar a los agraviados de los dos procesos penales instaurados en contra del quejoso, en su carácter de terceros interesados, por lo que si no se pudieran emplazar a la totalidad de ellos no se podría celebrar la audiencia constitucional, por ser un presupuesto procesal el principio de derecho de audiencia, lo cual da como consecuencia que no se dicte de manera pronta y expedita la sentencia de amparo.

- Impide el dictado de una sentencia respecto de un acto que legalmente no le compete conocer, en los casos en que se planteé demanda de garantías de la cual advierta que se cuestiona la constitucionalidad de actos cuya competencia corresponda, tanto a un Juez de Distrito como a un Tribunal Colegiado; este beneficio versa en relación con los juicios de amparo de los cuales tienen conocimiento los Tribunales Colegiados, cuando les es turnada una demanda que combata una sentencia definitiva emanada de un procedimiento jurisdiccional, laboral, administrativo, etcétera, y a su vez en la misma demanda se reclamen actos que no corresponde conocer a su competencia; sin embargo, sean procedentes en amparo indirecto, por lo cual al no estar facultados para conocer de los mismos separaría los juicio de amparo y se declinaría incompetente por un acto y por el otro conocería del asunto; lo anterior, porque no es procedente desechar respecto de los actos que no son competentes.

- La separación de juicios da oportunidad al quejoso para que pueda acreditar, mediante pruebas, la inconstitucionalidad de los actos que reclama y que son propios del conocimiento del juez de Distrito, esto es, cuando se reclama una resolución que pone fin a un procedimiento seguido en forma de juicio ante el cual no existe medio ordinario de defensa en su contra y, a su vez, se cuestiona un acto proveniente de una autoridad diversa de un tribunal judicial, administrativo o del trabajo; toda vez que no debe soslayarse que solo en el amparo indirecto se permite el ofrecimiento y admisión de pruebas tendentes a demostrar la inconstitucionalidad de los actos reclamados, mientras que en el amparo directo el acto debe ser analizado tal y como fue probado ante la responsable.

- El juzgador estará en posibilidad de dar solución adecuada al conflicto que se le ha planteado, salvaguardando así el derecho fundamental del gobernado a la impartición de justicia completa, pronta e imparcial. 
- Hace efectivo el principio de economía y celeridad procesal, en virtud de que con la separación de los juicios solo se constriñe a un acto materia de litis en el juicio de amparo, lo cual limita partes, como lo son terceros interesados innecesarios de emplazar, pruebas que no guarden relación con el acto reclamado y autoridades que no hayan tenido relación con la emisión del acto que por esa vía se combate, lo cual acelera la tramitación y economiza el procedimiento con comunicaciones y notificación oficiales innecesarias.

\section{Propuesta de la integración de la separación de juicios a la Ley de Amparo vigente}

Por todo lo anterior, se concluye que resulta procedente la propuesta de la integración de la figura procesal de la separación de juicios de amparo a la Ley de Amparo vigente.

\section{Estudios antecedentes}

De la revisión de los datos recabados, en la presente investigación se demuestra que existen investigaciones previas e incluso criterios jurisprudenciales emitidos por la Suprema Corte de Justicia de la Nación en relación con la separación de juicios, entre los más destacados encontramos los siguientes:

Jurisprudencia número P./J. 76/97, sustentada por el pleno de la Suprema Corte de Justicia de la Nación, visible en la página 118, del tomo VI, correspondiente al mes de septiembre de 1997, publicada en el Semanario Judicial de la Federación y su Gaceta, Novena Época, cuyo rubro y texto dicen:

SEPARACIÓN DE JUICIOS. SU PROCEDENCIA. Si en una demanda de amparo se reclaman actos emanados de juicios diversos, desvinculados entre sí, y dicha demanda ha sido admitida por el Juez de Distrito, o bien, tal circunstancia es advertida durante la tramitación del juicio (hasta antes de la celebración de la audiencia constitucional), con motivo de los informes justificados que rindan la o las autoridades responsables, podría iniciarse de oficio la separación de juicios, figura ésta, que al no estar específicamente regulada en la Ley de Amparo, debe por ello quedar contenida en la jurisprudencia, tomando como base el artículo 57 de esa ley, que establece la acumulación, deduciéndolo en sentido contrario, por lo que puede concluirse que, fuera de los casos que ahí se prevén, en cualquier otro supuesto se requiere hacer la separación.

Así también, encontramos la tesis número III. $2^{\circ}$. T.39 K, sustentada por el Segundo Tribunal Colegiado en Materia de Trabajo del Tercer Circuito, visible en la página 2810, del tomo XXXI, correspondiente al mes de abril de 2010, del Semanario Judicial de la Federación y su Gaceta, Novena Época, cuyo rubro y texto son los siguientes: 
SEPARACIÓN DE JUICIOS. DEBE DECRETARSE CUANDO DE LA DEMANDA DE AMPARO SE ADVIERTA QUE SE CUESTIONA LA CONSTITUCIONALIDAD DE ACTOS CUYO CONOCIMIENTO DEBA TRAMITARSE EN DIVERSAS VÍAS, SIEMPRE Y CUANDO ESTOS TENGAN EXISTENCIA AUTÓNOMA Y NO DEPENDAN ENTRE SÍ. El Pleno de la Suprema Corte de Justicia de la Nación en la jurisprudencia por contradicción de tesis P./J. 76/97, publicada en el Semanario Judicial de la Federación y su Gaceta, Novena Época, Tomo VI, septiembre de 1997, página 118, de rubro: "SEPARACIÓN DE JUICIOS. SU PROCEDENCIA", estableció que aun cuando la figura de "separación" no esté regulada específicamente por la Ley de Amparo, ésta debe ser implementada aplicando en sentido contrario las disposiciones que regulan la acumulación de juicios precisadas por el artículo 57 de ese ordenamiento, cuando del texto de la demanda de amparo se advierta que se reclaman actos provenientes de diversos juicios; lo que tiene como finalidad evitar el dictado de una sentencia incongruente consigo misma, con la consecuente problemática que implicaría su cumplimiento. En tales condiciones y, considerando los mismos principios que sirvieron de fundamento a la referida jurisprudencia, es claro que a fin de no crear una incertidumbre jurídica y a su vez denegar justicia a quien acude a solicitar la protección de la Justicia Federal, cuando de la demanda de garantías se advierta que se cuestiona la constitucionalidad de actos cuya competencia corresponda, por ejemplo, tanto a un Juez de Distrito como a un Tribunal Colegiado, debe decretarse la separación de juicios, para que se evite el dictado de una sentencia respecto de un acto que legalmente no le compete conocer y a su vez, se dé oportunidad al quejoso para que pueda acreditar mediante pruebas, la inconstitucionalidad de los actos que reclama y que son propios del conocimiento del Juez de Distrito, esto es, cuando se reclama una resolución que pone fin a un procedimiento seguido en forma de juicio ante el cual no existe medio ordinario de defensa en su contra y, a su vez, se cuestiona un acto proveniente de una autoridad diversa de un tribunal judicial, administrativo o del trabajo en términos de la fracción II del artículo 114 de la Ley de Amparo; toda vez que no debe soslayarse que sólo en el amparo indirecto se permite el ofrecimiento y admisión de pruebas tendentes a demostrar la inconstitucionalidad de los actos reclamados, mientras que en el amparo directo el acto debe ser analizado tal y como fue probado ante la responsable; lo anterior desde luego, siempre y cuando los actos reclamados en la demanda tengan existencia autónoma y no dependan entre sí, es decir, que no sean consecuencia uno del otro, o que persigan el mismo objeto procesal, pues de resultar así, no debe decretarse la separación, en virtud de que no es factible dividir la continencia de la causa.

Finalmente, se tiene la jurisprudencia número P./J. 77/97, sustentada por el pleno de la Suprema Corte de Justicia de la Nación, visible en la página 118 del tomo VI, correspondiente al mes de septiembre de 1997 del Semanario Judicial de la Federación y su Gaceta, Novena Época, en la cual se señala las reglas de la tramitación de la separación de juicios en materia de amparo, la cual refiere: 
SEPARACIÓN DE JUICIOS. REGLAS PARA SU TRAMITACIÓN EN EL JUICIO DE GARANTÍAS. La separación de juicios podrá válidamente hacerse de oficio en cualquier estado del procedimiento, desde la etapa de la admisión de la demanda hasta antes de la celebración de la audiencia constitucional. El trámite deberá ser incidental, aplicando, en lo pertinente, los preceptos legales de la Ley de Amparo relativos a la acumulación, en sentido contrario, con suspensión del procedimiento principal, como lo establece el artículo 62 de dicha ley, con audiencia de las partes y resolución que decrete la separación. El Juez, en esta etapa, podrá hacer los requerimientos necesarios a las partes, aplicando por analogía lo dispuesto en el artículo 78 de la ley de la materia, para conocimiento pleno de lo que resolverá.

\section{CONCLUSIONES}

Los resultados del estudio de la problemática sobre la cual verso el presente trabajo de investigación fueron satisfactorios, en virtud de que se estudió la factibilidad de la integración de la figura procesal de la separación de juicios de amparo, a la actual de ley de la materia, desde diversos puntos críticos para corroborar tal propuesta, lo cual dio oportunidad a sopesar si resultaba procedente tal adicción, a través de analizar los beneficios que consigo traía la incorporación de la separación de los actos reclamados cuando no tengan ninguna relación entre sí, y con ello evitar sentencias engorrosas, extensas y confusas, así como un sin fin de dilaciones al procedimiento de amparo.

Por su parte, se cumplieron los objetivos específicos de la presente investigación, como lo fue entrar al estudio de la tramitación del juicio de amparo el cual tuvo serias modificaciones con la reforma en materia de amparo. También se logró conocer el origen de la jurisprudencia que dio sustento a la figura procesal de la separación de juicio, detallando la ejecutoria que resolvió la Suprema Corte de Justicia de la Nación.

\section{Propuesta de adición de la figura procesal separación de juicios a la Ley de Amparo}

Una vez expuestos los razonamientos con los cuales se defiende la solución al problema que se plantea, se concluyó que resulta viable la propuesta de la integración de la separación de juicios en la Ley de Amparo vigente, con el objetivo de crear certidumbre jurídica, eliminar la denegación de justicia pronta y expedita a quien acude a solicitar la protección de la Justicia Federal, así como para evitar el dictado de una sentencia incongruente consigo misma y consecuentemente una problemática en llevar a cabo su cumplimiento; máxime que dicha figura procesal no contraviene ninguna de las disposiciones contenidas en la aludida legislación.

Asimismo, se considera que los resultados obtenidos fueron muy satisfactorios al ampliar los conocimientos de la materia, así como a definir las ideas propuestas y orientarlas al tema de estudio, con lo cual se logró el cometido final que era realizar 
un estudio a fondo respecto de la procedencia de integrar la multicitada figura procesal en el ordenamiento legal de amparo, lo anterior, con preponderando los beneficios con las desventajas de dicha propuesta; sin embargo, al parecer todos los resultados fueron convincentes, toda vez que surgieron un sin número de beneficios que aporta la separación de juicios al trámite del juicio de amparo y más importante a la resolución que se dicta en definitiva.

De igual forma, resultó vital para el estudio de esta investigación analizar el impacto de la reforma de amparo, con motivo de la publicación de la nueva Ley de Amparo el dos de abril de dos mil trece, en el diario oficial de la federación, con ampliación obligatoria a partir de la fecha se su publicación y repercusión que tuvo en lo especifico en la separación de juicios de amparo.

Finalmente se precisaron de manera clara y práctica los múltiples beneficios que genera la propuesta de adicionar a la Ley de Amparo la figura procesal de la separación de juicios.

\section{REFERENCIAS}

Arellano, C. (2012). El juicio de amparo. México: Porrúa.

Burgoa, I. (2010). Juicio de amparo. México: Porrúa.

Chávez, R. (2013). Juicio de amparo. México: Porrúa.

Góngora, G. (2010). Introducción al estudio del juicio de amparo. México: Porrúa.

Romero, R. (2012). Análisis del Proyecto de Nueva Ley de Amparo. Memoria de la Jornada de Actualización Jurídica. México: UNAM.

Ruiz, I. (2009). La acción de amparo. Derecho Público. Universidad Autónoma de Ciudad Juárez. México.

Suprema Corte de Justicia de la Nación. (2012). Manual del juicio de amparo. México: Themis.

Suprema Corte de Justicia de la Nación, Poder Judicial de la Federación. (2012). Manual del justiciable. Elementos de teoría general del proceso. México.

Suprema Corte de Justicia de la Nación, Poder Judicial de la Federación. (2012). Manual del justiciable en materia de amparo. México.

Tamayo y Salmorán, R. (2012). Razonamiento y argumentaciónjurídica. El paradigma de la racionalidad y la ciencia del derecho. Instituto de Investigaciones Jurídicas. México: UNAM.

Torruco, J. (2013). Teoría de la Constitución. Origen y desarrollo de las constituciones mexicanas. Normas e instituciones de la Constitución de 1917. México: Porrúa. 


\section{Legisgrafía}

Constitución Política de los Estados Unidos Mexicanos. (2015). México: Porrúa.

Ley de Amparo. Reglamentaria de los artículos 103 y 107 de la Constitución Política. (2013). México: Editorial ISEF.

Suprema Corte de Justicia de la Nación. (1997). Separación de juicios. Reglas para su tramitación en el juicio de garantías. [J]; 9ª Época; Pleno; S.J.F. y su Gaceta; tomo VI, septiembre de 1997, p. 118.

Suprema Corte de Justicia de la Nación. (2013). Separación de juicios. Su procedencia. [J]; 9a. Época; Pleno; S.J.F. y su Gaceta; Tomo VI, septiembre de 1997, p. 118 [CD]

Tribunales Colegiados de Circuito. (1994). Amparo. Principio de instancia de parte agraviada, caso en que no se cumple. $8^{\text {a }}$. Época; TCC; S.J.F.; tomo XIV, septiembre de 1994, p. 259 [CD]

Tribunales Colegiados de Circuito. (2002). Jurisprudencia de la Suprema Corte de Justicia. Obligatoriedad. [J]; 9a. Época; T.C.C.; S.J.F. y su Gaceta; tomo XV, marzo de 2002, p. 1225.

Tribunales Colegiados de Circuito. (2002). Separación de juicios. El Tribunal Revisor puede ordenarla decretando la reposición del procedimiento, si fue omiso el $a$ quo en efectuarla. [TA]; 9. Época; T.C.C.; S.J.F. y su Gaceta; tomo XVI, agosto de 2002, p. 1387.

Tribunales Colegiados de Circuito. (2008). Separación de juicios. Procede cuando en amparo directo se reclama conjuntamente con una sentencia definitiva o resolución que pone fin al juicio la resolución que no admite la denuncia del juicio a terceros. [TA]; 9a. Época; T.C.C.; S.J.F. y su Gaceta; tomo XXVIII, septiembre de 2008, p. 1414.

\section{Internet}

Campos, R. (s.f.). El juicio de amparo, carencias, imperfecciones y puntos patológicos a sus 154 años de nacimiento. Recuperado de http://www.juridicas.unam.mx/ publica/librev/rev/refjud/cont/1/cle/cle13.pdf

Diccionario Jurídico. Recuperado de http://www.diccionariojuridico.mx/

Tribunales Colegiados de Circuito. (2003). Jurisprudencia. Concepto, clases y fines. [TA]; 9a. Época; T.C.C.; S.J.F. y su Gaceta; tomo XVIII, octubre de 2003; p. 1039. Recuperado de http://sjf.scjn.gob.mx/sjfsist/Paginas/DetalleGeneralV2.aspx?

Tribunales Colegiados de Circuito. (2010). Separación de juicios. Debe decretarse cuando de la demanda de amparo se advierta que se cuestiona la constitucionalidad de actos cuyo conocimiento deba tramitarse en diversas vías, siempre y cuando éstos tengan existencia autónoma y no dependan entre sí. [TA]; 9a. Época; T.C.C.; S.J.F. y su Gaceta; tomo XXXI, abril de 2010, p. 2810. Recuperado de http://ius.scjn.gob.mx/paginas/DetalleGeneralV2.aspx?ID=164 $678 \&$ Clase $=$ DetalleTesisBL 